Published in final edited form as:

Nat Methods. 2019 January ; 16(1): 95-102. doi:10.1038/s41592-018-0232-7.

\title{
A pH-correctable, DNA-based fluorescent reporter for organellar Calcium
}

\author{
Nagarjun Narayanaswamy $\#, 1,2$, Kasturi Chakraborty $\#, 1,2,{ }^{*}$, Anand Saminathan ${ }^{1,2}$, Elizabeth \\ Zeichner $^{1}$, KaHo Leung ${ }^{1,2}$, John Devany ${ }^{3}$, Yamuna Krishnan ${ }^{1,2,{ }^{*}}$ \\ ${ }^{1}$ Department of Chemistry, The University of Chicago, Chicago, Illinois 60637, USA. \\ ${ }^{2}$ Grossman Institute of Neuroscience, Quantitative Biology and Human Behavior, The University \\ of Chicago, Chicago, Illinois 60637, USA. \\ ${ }^{3}$ Department of Physics, The University of Chicago, IL, 60637, USA
}

\section{Abstract}

It is extremely challenging to quantitate lumenal $\mathrm{Ca}^{2+}$ in acidic $\mathrm{Ca}^{2+}$ stores of the cell because all $\mathrm{Ca}^{2+}$ indicators are $\mathrm{pH}$ sensitive, and $\mathrm{Ca}^{2+}$ transport coupled to $\mathrm{pH}$ in acidic organelles. We have developed a fluorescent DNA-based reporter, CalipHluor, that is targetable to specific organelles. By ratiometrically reporting lumenal $\mathrm{pH}$ and $\mathrm{Ca}^{2+}$ simultaneously, it functions as a $\mathrm{pH}-$ correctable, $\mathrm{Ca}^{2+}$ reporter. By targeting CalipHluor to the endolysosomal pathway we mapped lumenal $\mathrm{Ca}^{2+}$ changes during endosomal maturation and found a surge in lumenal $\mathrm{Ca}^{2+}$ specifically in lysosomes. Using lysosomal proteomics and genetic analysis we found that catp-6, a C. elegans homolog of ATP13A2, was responsible for lysosomal $\mathrm{Ca}^{2+}$ accumulation - the first example of a lysosome-specific $\mathrm{Ca}^{2+}$ importer in animals. By enabling the facile quantification of compartmentalized $\mathrm{Ca}^{2+}$, CalipHluor can expand our understanding of subcellular $\mathrm{Ca}^{2+}$ importers.

\section{Introduction}

$\mathrm{Ca}^{2+}$ regulates diverse cellular functions upon its controlled release from different intracellular stores that initiates signaling cascadeszz ${ }^{1,2}$. Lysosomes have recently been recognized as "acidic $\mathrm{Ca}^{2+}$ stores", and lumenal $\mathrm{Ca}^{2+}$ is central to its diverse functions ${ }^{3}$. Lysosome function is particularly important in neurons given the preponderance of lysosome-related genes in diverse neurological disorders including 60 lysosomal storage disorders ${ }^{4}$. For example, risk genes for Parkinsons disease such as LRRK2, ATP6AP2, ATP13A2, and genetic risk associated GBA1 gene, are predicted to act in lysosomal pathways ${ }^{5}$.

\footnotetext{
"Corresponding authors.yamuna@uchicago.edu; kasturi@uchicago.edu.

\#These authors contributed equally to this work.

Author Contributions

K.C. and Y.K. designed the project. N.N synthesized and designed the calcium dye. N.N., K.C., A.S., E.H.Z., K.L., performed experiments. J.D. provided key resources. N.N., K.C., A.S, and Y.K. analyzed the data. K.C. and Y.K wrote the paper. All authors discussed the results and gave inputs on the manuscript.

Competing financial interests

The authors declare no competing financial interests.
} 
Although electrophysiology has enabled the discovery of several channels that release lysosomal $\mathrm{Ca}^{2+}$, mediators of lysosomal $\mathrm{Ca}^{2+}$ import have not yet been identified ${ }^{3,6}$. Lysosomal $\mathrm{Ca}^{2+}$ release channels are amenable to investigation because $\mathrm{Ca}^{2+}$ release can be tracked using cytosolic $\mathrm{Ca}^{2+}$ dyes or genetically encoded $\mathrm{Ca}^{2+}$ indicators anchored to the cytoplasmic face of the lysosome ${ }^{7-9}$. Upon $\mathrm{Ca}^{2+}$ release, these probes indicate cytosolic $\mathrm{Ca}^{2+}$ in the area surrounding lysosomes. In contrast, lumenal $\mathrm{Ca}^{2+}$ cannot be quantitated, impeding the study of lysosomal $\mathrm{Ca}^{2+}$ importers. Consequently, lysosomal $\mathrm{Ca}^{2+}$ importers have not yet been identified in animals ${ }^{10}$, with the closest evidence being that the Xenopus CAX gene localizes in lysosomes upon overexpression ${ }^{11}$.

The inability to quantify $\mathrm{Ca}^{2+}$ in acidic organelles arises because all $\mathrm{Ca}^{2+}$ indicators function by coordinating $\mathrm{Ca}^{2+}$ through carboxylate groups that get protonated at acidic $\mathrm{pH}^{12}$. This changes probe affinity to $\mathrm{Ca}^{2+}$ ions. Further, organellar $\mathrm{pH}$ is coupled to lumenal $\mathrm{Ca}^{2+}$ entry and exit ${ }^{13}$. Thus, it is non-trivial to deconvolute the contribution of $\mathrm{Ca}^{2+}$ to the observed fluorescence changes of any $\mathrm{Ca}^{2+}$ indicator. Previous attempts used endocytic tracers bearing either $\mathrm{pH}$ or $\mathrm{Ca}^{2+}$ sensitive dyes to serially measure population-averaged $\mathrm{pH}$ and apparent $\mathrm{Ca}^{2+}$ in different batches of cells thus, scrambling information from individual endosomes ${ }^{13-17}$. Given the broad $\mathrm{pH}$ distribution in endocytic organelles, this approach does not provide the resolution needed to study $\mathrm{Ca}^{2+}$ import $^{18}$.

Here, we use a combination reporter for $\mathrm{pH}$ and $\mathrm{Ca}^{2+}$ to map both ions in parallel in the same endosome with single endosome addressability, achieving highly accurate measures of lumenal $\mathrm{Ca}^{2+}$. Using the $\mathrm{pH}$ reporter module of the combination reporter we deduce the $\mathrm{pH}$ in individual endosomes. By knowing exactly how the affinity of the $\mathrm{Ca}^{2+}$ sensitive module, i.e., its dissociation constant, $\mathrm{K}_{\mathrm{d}}$, changes with $\mathrm{pH}$, we apply a $\mathrm{K}_{\mathrm{d}}$ correction factor suited to the lumenal $\mathrm{pH}$ of each endosome to thereby compute the true value of lumenal $\mathrm{Ca}^{2+}$ with single-endosome resolution.

DNA nanodevices are versatile chemical reporters that can quantitatively map second messengers in real time, in living systems ${ }^{19-22}$. The modularity of DNA allows us to integrate distinct functions in precise stoichiometries into a single assembly. These include (i) a module to fluorescently sense a given ion (ii) a normalizing module for ratiometric quantitation and (iii) a targeting module to localize the reporter in a specific organelle ${ }^{19}$. We have thus measured $\mathrm{H}^{+}$and $\mathrm{Cl}^{-}$in endocytic organelles ${ }^{20-24}$. Here we describe a DNAbased fluorescent reporter, CalipHluor, to quantitatively map organellar $\mathrm{pH}$ and $\mathrm{Ca}^{2+}$ simultaneously and with single organelle addressability. CalipHluor comprises four modules: a pH sensitive module; a $\mathrm{Ca}^{2+}$ sensitive fluorophore; an internal reference dye to ratiometrically quantitate $\mathrm{pH}$ as well as $\mathrm{Ca}^{2+}$ and finally, a targeting domain to transport CalipHluor to a specific organelle.

By targeting CalipHluor to the scavenger receptor-mediated endocytic pathway, we mapped lumenal $\mathrm{Ca}^{2+}$ as a function of endosomal maturation in nematodes. We found that $\mathrm{Ca}^{2+}$ is fairly low in early and late endosomes, followed by a $\sim 35$ fold surge in lumenal $\mathrm{Ca}^{2+}$ in lysosomes - implicating the existence of lysosome-specific $\mathrm{Ca}^{2+}$ import mechanisms. We identified the P5 $\mathrm{Ca}^{2+}$ ATPase ATP13A2 as a potential candidate given its similarity to a well-known $\mathrm{Ca}^{2+}$ importer in the endoplasmic reticulum ${ }^{25}$. ATP13A2 transports divalent 
ions such as $\mathrm{Mg}^{2+}, \mathrm{Mn}^{2+}, \mathrm{Cd}^{2+}, \mathrm{Zn}^{2+}$ yet, has not been tested for its ability to transport $\mathrm{Ca}^{2+26,27}$. We showed that the $C$. elegans homolog of ATP13A2, catp-6, functions in opposition to the well-known lysosomal $\mathrm{Ca}^{2+}$ release channel, cup- $5^{28}$. We then showed that the human homolog, ATP13A2 also facilitates lysosomal $\mathrm{Ca}^{2+}$ entry by measuring lysosomal $\mathrm{Ca}^{2+}$ in fibroblasts derived from patients with Kufor Rakeb Syndrome. This constitutes the first example of a lysosomal $\mathrm{Ca}^{2+}$ importer in the animal kingdom.

\section{Results and Discussion}

\section{Design and in vitro characterization of CalipHluor}

We describe the design and characterization of a fluorescent, DNA-based combination reporter for $\mathrm{pH}$ and $\mathrm{Ca}^{2+}$ called CalipHluor $_{L y}$. CalipHluor $_{L y}$ is a 57-base pair DNA duplex comprising two strands D1 and D2 and bears three distinct domains (Fig. 1a, Supplementary Table S1). The first domain in CalipHluor $_{L y}$ is a $\mathrm{Ca}^{2+}$-reporter domain that uses a novel small molecule that functions as a $\mathrm{Ca}^{2+}$ indicator that we denote Rhod- $5 \mathrm{~F}^{29}$. Rhod-5F consists of a BAPTA core, a rhodamine fluorophore $\left(\lambda_{\mathrm{ex}}=560 \mathrm{~nm} ; \lambda_{\mathrm{em}}=580 \mathrm{~nm}\right)$ and an azide linker. In the absence of $\mathrm{Ca}^{2+}$, the rhodamine fluorophore in Rhod-5F is quenched by photoinduced electron transfer (PeT) from the BAPTA core. Upon $\mathrm{Ca}^{2+}$ chelation quenching is relieved resulting in high fluorescence. Note that protonation of the amines in BAPTA also relieves $\mathrm{PeT}^{12}$. Thus the percentage change in signal as well as the dissociation constant $\left(\mathrm{K}_{\mathrm{d}}\right)$ in Rhod-5F will be affected as a function of $\mathrm{pH}$. The $\mathrm{K}_{\mathrm{d}}$ of Rhod-5F for $\mathrm{Ca}^{2+}$ binding is indeed $\mathrm{pH}$ dependent and shown in the supplementary information (Supplementary Fig. S1).

Rhod-5F is attached to the $\mathrm{D} 2$ strand bearing a dibenzocyclooctyne (DBCO) group using click chemistry ${ }^{30}$. Conjugation to D2 did not change the $\mathrm{K}_{\mathrm{d}}$ of Rhod-5F in CalipHluor $\mathrm{r}_{\mathrm{L}}$ (Fig. 1b). In CalipHluor Ly Rhod-5F (O, orange diamond) shows a $\mathrm{K}_{\mathrm{d}}$ of $1.1 \mu \mathrm{M}$ at $\mathrm{pH} 7.2$ which increases as acidity increases (Fig. 1b).

For ratiometric quantification of $\mathrm{Ca}^{2+}$ we incorporate Alexa 647 as a reference dye $\left(\lambda_{\mathrm{ex}}=\right.$ $630 \mathrm{~nm} ; \lambda_{\mathrm{em}}=665 \mathrm{~nm}$ ) on CalipHluor $_{L y}$ positioned so that it does not FRET with Rhod-5F. Alexa 647 was chosen for its negligible spectral overlap with Rhod-5F and insensitivity to $\mathrm{pH}, \mathrm{Ca}^{2+}$ and other ions (red circle, Fig. 1a). The fixed stoichiometry of Alexa 647 efficiently corrects for Rhod-5F intensity changes due to inhomogeneous probe distribution in cells, thus making the ratio of Rhod-5F (O) and Alexa $647(\mathrm{R})$ intensities in CalipHluor probes proportional to $\mathrm{pH}$ and $\mathrm{Ca}^{2+}$. The second domain (gray line) constitutes a DNA based $\mathrm{pH}$-reporter domain that we have previously described, called the $I$-switch ${ }^{20}$ (Fig. 1a). This $I-s w i t c h$ has been used to map $\mathrm{pH}$ in diverse endocytic organelles in living cells ${ }^{20-24}$. To map pH in early and late endosomes we made CalipHluor, a variant suited to the lower acidities in these organelles (Supplementary Table S1 and Fig. S2c). CalipHluor and CalipHluor $_{L y}$ were formed and characterized by gel electrophoresis (Supplementary Fig. S2 $\mathrm{a}-\mathrm{e})$. The third 'integration' domain comprises a 30-mer duplex, that integrates the $\mathrm{pH}$ and the $\mathrm{Ca}^{2+}$ reporter domains into a single DNA assembly. One end is fused to the I-switch and the other is fused to the $\mathrm{Ca}^{2+}$ sensor. This domain also helps in targeting, because its anionic nature aids recognition and trafficking by scavenger receptors in a DNA sequence independent manner ${ }^{21}$. 
The response characteristics of CalipHluor and CalipHluor ${ }_{L y}$ were investigated as a function of $\mathrm{pH}$ as well as $\mathrm{Ca}^{2+}$ and their $\mathrm{pH}$ and $\mathrm{Ca}^{2+}$ sensitive regimes were determined (Fig. 1c-d and Supplementary Fig. S2f-g). A 3D surface plot of D/A as a function of $\mathrm{pH}$ and different values of free $\left[\mathrm{Ca}^{2+}\right]$ is shown in Fig. 1c. These revealed that the $\mathrm{pH}$ reporting capabilities of CalipHluor and CalipHluor $L_{L y}$ are between $\mathrm{pH} 5.0-7.0$ and $\mathrm{pH} 4.0-6.5$ with fold changes in D/A ratios of 4.0 and 5.5 respectively (Fig. 1c) ${ }^{21}$. Notably, the fold changes in D/A ratios were invariant over a range of free $\mathrm{Ca}^{2+}$ concentrations from $20 \mathrm{nM}-10 \mathrm{mM}$ showing that pH sensing by these probes is unaffected by $\mathrm{Ca}^{2+}$ levels (Fig. 1c).

In parallel, the intensities of Rhod-5F (O) and Alexa647 (R) in CalipHluor ${ }_{L y}$ obtained from direct excitation yielded $\mathrm{O} / \mathrm{R}$ values. An analogous $3 \mathrm{D}$ surface plot of $\mathrm{O} / \mathrm{R}$ values as a function of $\left[\mathrm{Ca}^{2+}\right]$ and $\mathrm{pH}$ showed a sigmoidal increase as a function of $\mathrm{Ca}^{2+}$ with a $\sim 9$ fold change in $\mathrm{O} / \mathrm{R}$ at pH 7.2 (Fig. 1d). At lysosomal pH in C. elegans, i.e., pH 5.5, CalipHluor ${ }_{L y}$ showed a $\mathrm{K}_{\mathrm{d}}$ of $7.2 \mu \mathrm{M}$. As expected, the percentage signal change upon chelating $\mathrm{Ca}^{2+}$ also decreases as acidity increases (Fig. 1d).

\section{In vivo performance of CalipHluor.}

Next, we investigated the in vivo reporter characteristics of CalipHIuor $_{L y}$ as a function of lumenal $\mathrm{pH}$ and $\left[\mathrm{Ca}^{2+}\right]$. When DNA-based reporters are injected into the pseudocoelom in $C$. elegans they are specifically uptaken by coelomocytes through the scavenger receptors mediated endocytosis and thereby label organelles on the endolysosomal pathway ${ }^{21,24}$. After labeling endocytic organelles with CalipHluor $_{L y}$ thus, we clamped lumenal $\mathrm{pH}$ and $\left[\mathrm{Ca}^{2+}\right]$ of coelomocytes. This was achieved by incubating worms in clamping buffers of fixed $\mathrm{pH}$ and $\left[\mathrm{Ca}^{2+}\right]$ containing nigericin, monensin, ionomycin and EGTA at high $\left[\mathrm{K}^{+}\right]$which clamped the endosomal ionic milieu to that of the surrounding buffer (Methods) ${ }^{13,15,22,24}$. Postclamping, the worms were then imaged in four channels; (i) the donor channel (D or Alexa 488) (ii) the FRET acceptor channel (A), which corresponds to the intensity image of A647 fluorescence upon exciting A488, (iii) the orange channel (O or Rhod-5F), and (iv) the red channel (R) which corresponds to the intensity image of A647 fluorescence upon directly exciting Alexa 647. Fig. 2a (i - iv) shows representative images of a CalipHluor $_{L y}$ labeled coelomocyte imaged in the four channels.

In a given clamping buffer of specified $\mathrm{pH}$ and $\mathrm{Ca}^{2+}$ concentration, the ratio of the donor channel (D) image to the acceptor channel (A) image yields a D/A image which corresponds to the clamping buffer $\mathrm{pH}$ (Fig. $2 \mathrm{a}(\mathbf{v})$ ). Similarly, the O/R image corresponds to the $\mathrm{Ca}^{2+}$ concentration at that $\mathrm{pH}$ (Fig. 2a (vi)). Representative D/A and O/R images of coelomocytes clamped at the indicated $\mathrm{pH}$ and $\left[\mathrm{Ca}^{2+}\right]$ are shown in Figure $2 \mathrm{~b}$ (Methods)(Supplementary Fig. S3). The distribution of D/A and O/R values of lysosomes clamped at different indicated $\mathrm{pH}$ and $\left[\mathrm{Ca}^{2+}\right]$ values are shown in Figures $2 \mathrm{c}-\mathrm{d}$. To compare the in vivo and in vitro sensing performances of both ion-sensing modules across a wide range of $\mathrm{pH}$ and $\mathrm{Ca}^{2+}$ we plotted two parameters for each module in CalipHluor $_{\mathrm{Ly}}$. For the $\mathrm{pH}$ sensing module these were the fold change in $\mathrm{D} / \mathrm{A}\left(\mathrm{FC}_{\mathrm{D} / \mathrm{A}}\right)$, as well as the transition $\mathrm{pH}\left(\mathrm{pH}_{1 / 2}\right)(\mathrm{Fig}$. $2 \mathrm{e}-\mathrm{f}$, Supplementary Fig. $\mathrm{S} 4 \mathrm{a}-\mathrm{d})$. For the $\mathrm{Ca}^{2+}$ sensing module, these were the fold change in $\mathrm{O} / \mathrm{R}\left(\mathrm{FC}_{\mathrm{O} / \mathrm{R}}\right)$ as well as the $\mathrm{K}_{\mathrm{d}}$ for $\mathrm{Ca}^{2+}(\mathrm{Fig} .2 \mathrm{~g}-\mathrm{h})$. The values of $\mathrm{FC}_{\mathrm{D} / \mathrm{A}}, \mathrm{FC}_{\mathrm{O} / \mathrm{R}}, \mathrm{pH}_{1 / 2}$ and 
$\mathrm{K}_{\mathrm{d}}$ in vivo and in vitro were consistent revealing that the in vitro performance characteristics of CalipHluor $L_{\text {Ly }}$ was quantitatively recapitulated in vivo (Fig. 2e-f and Fig 2i-k).

\section{Measuring $\left[\mathrm{Ca}^{2+}\right]$ in organelles of the endo-lysosomal pathway}

Endosomal maturation, critical to both organelle function and cargo trafficking, is accompanied by progressive acidification of the organelle lumen (Fig. 3a $)^{31,32}$. Unlike pH, little is known about lumenal $\mathrm{Ca}^{2+}$ changes as a function of endosomal maturation ${ }^{16,17}$. We therefore sought to demonstrate the applicability of our probe across a range of acidic organelles by mapping lumenal $\mathrm{Ca}^{2+}$ as a function of endosomal maturation. We determined the time points at which CalipHluor $_{L y}$ localized in the early endosome, the late endosome and the lysosome in coelomocytes as described previously ${ }^{21}$ (Fig. 3b-c). Post injection, CalipHluor $_{L y}$ was found to localize in early endosomes (EE), late endosomes (LE) and lysosomes (LY) at 5, 17 and 60 mins respectively (Fig. 3b-c, Supplementary Fig. S5).

We measured $\mathrm{pH}$ and apparent $\mathrm{Ca}^{2+}$ at each stage in wild type $\mathrm{N} 2$ nematodes with single endosome addressability using our probes. We then incorporated a $\mathrm{K}_{\mathrm{d}}$ correction factor for each endosome according to its measured $\mathrm{pH}$, and then computed the true value of $\mathrm{Ca}^{2+}$ in every endosome. Figure $3 \mathrm{~d}$ shows a representative set of coelomocytes for which this method of analysis was performed. We labeled early and late endosomes with CalipHluor whereas we labeled lysosomes with the CalipHluor $_{L y}$ variant and then generated the D/A and O/R maps of coelomocytes (Methods, Fig. 3d (i) \& (iv)). The D/A map was directly converted into a $\mathrm{pH}$ map using the calibrated $\mathrm{D} / \mathrm{A}$ values obtained from the in vivo $\mathrm{pH}$ clamping experiments (Fig. 3d(ii), Supplementary Table S2). The in vivo and in vitro $\mathrm{Ca}^{2+}$ response characteristics at every $\mathrm{pH}$ (Fig. $2 \mathrm{~h}$ ), provides the $\mathrm{K}_{\mathrm{d}}$ for $\mathrm{Ca}^{2+}$ at every $\mathrm{pH}$ value for both CalipHluor and CalipHluor $L$.

Using the $\mathrm{pH}$ map in Fig. 3d (ii) we constructed a " $\mathrm{K}_{\mathrm{d}}$ map" which corresponds to the $\mathrm{K}_{\mathrm{d}}$ for $\mathrm{Ca}^{2+}$ at each pixel in the $\mathrm{pH}$ map (Fig. 3d (iii), Supplementary Methods). Multiplying the value of $K_{d}$ at each pixel in the $K_{d}$ map with the equation $\left(O / R-O / R_{\min }\right) /\left(O / R_{\max }-O / R\right)$ we obtain the true $\mathrm{Ca}^{2+}$ map (Fig. $3 \mathrm{~d}(\mathbf{v})$ ). In this equation, $\mathrm{O} / \mathrm{R}$ corresponds to the observed $\mathrm{O} / \mathrm{R}$ value at a given pixel in the $\mathrm{O} / \mathrm{R}$ map, $\mathrm{O} / \mathrm{R}_{\min }$ and $\mathrm{O} / \mathrm{R}_{\max }$ correspond to $\mathrm{O} / \mathrm{R}$ values at $1 \mu \mathrm{M}$ and $10 \mathrm{mM} \mathrm{Ca}^{2+}$ at the corresponding $\mathrm{pH}$ value at that particular pixel. We thus obtained $\mathrm{pH}$ and $\mathrm{Ca}^{2+}$ maps of early endosomes, late endosomes and lysosomes in $\mathrm{N} 2$ worms (Fig. 3e) and the corresponding distributions of D/A and $\mathrm{pH}$-corrected O/R are shown in Figures $3 \mathrm{f}-$ g. The mean values of $\mathrm{pH}$ and $\mathrm{Ca}^{2+}$ in each endosomal stage is shown in Figures $3 \mathrm{~h}-\mathrm{i}$.

As expected, $\mathrm{pH}$ decreases progressively with endosomal maturation, with lumenal acidity showing a $\sim 3$-fold decrease at each endocytic stage. In contrast, $\mathrm{Ca}^{2+}$ in the early endosome and the late endosome were comparable and fairly low i.e., $0.3 \mu \mathrm{M}$. Interestingly, from the late endosome to the lysosome, lumenal $\mathrm{Ca}^{2+}$ increases sharply by $\sim 35$ fold, indicating a stage-specific enrichment of $\mathrm{Ca}^{2+}$ and consistent with the lysosome being an acidic $\mathrm{Ca}^{2+}$ store (Supplementary Table S3). The 100-fold difference between lysosomal and cytosolic $\mathrm{Ca}^{2+}$ is consistent with the stringent regulation of lysosomal $\mathrm{Ca}^{2+}$ channels to release lumenal $\mathrm{Ca}^{2+}$ and control lysosome function. 


\section{Catp- 6 is identified as a potential lysosomal $\mathrm{Ca}^{2+}$ importer}

This surge in lumenal $\mathrm{Ca}^{2+}$ specifically in the lysosome stage, implicates the existence of factors that aid lysosomal import of $\mathrm{Ca}^{2+}$. However, players that mediate lysosomal $\mathrm{Ca}^{2+}$ accumulation are still unknown in higher eukaryotes. We took inspiration from the wellknown $\mathrm{Ca}^{2+}$ importer i.e., SERCA, a P-Type ATPase which is present on the endoplasmic reticulum $(\mathrm{ER})^{25}$. Other $\mathrm{Ca}^{2+}$ importers like plasma membrane $\mathrm{Ca}^{2+}$ ATPase (PMCA) and the secretory pathway $\mathrm{Ca}^{2+}$ ATPase (SPCA1) are also P-type-ATPases ${ }^{33}$. Therefore we manually identified potential P-type ATPases in the human lysosomal proteome ${ }^{34-38}$. We found the P5-ATPase ATP13A2 was described to transport cations like $\mathrm{Mn}^{2+}, \mathrm{Zn}^{2+}, \mathrm{Mg}^{2+}$, and $\mathrm{Cd}^{2+}$ but not $\mathrm{Ca}^{2+}$ based on toxicity assays ${ }^{26}$. $\mathrm{As} \mathrm{Ca}^{2+}$ homeostasis is critical to all major signaling pathways, compensatory mechanisms in cells can counter excess $\mathrm{Ca}^{2+}$ and thereby omit the identification of $\mathrm{Ca}^{2+}$ transport by ATP13A2.

C. elegans has two homologs of ATP13A2 i.e., catp-5 and catp-6 (Fig. 4a). To test whether catp-6 mediated lysosomal $\mathrm{Ca}^{2+}$ accumulation, we investigated whether its knockdown would rescue a phenotype arising due to high lumenal $\mathrm{Ca}^{2+}$ (Fig. 4b). TRPML1 is a wellknown lysosomal $\mathrm{Ca}^{2+}$ release channel whose knockdown would be expected to elevate lysosomal $\mathrm{Ca}^{2+39,40}$. Mutations in TRPML1 result in lysosomal dysfunction that leads to the lysosomal storage disease Mucopolysaccharidoses Type IV (MPS IV) ${ }^{41}$. In C. elegans, loss of cup-5, the $C$. elegans homolog of TRPML1, results in lysosomal storage and embryonic lethality ${ }^{42}$. We therefore tested whether catp-6 knockdown a cup-5+/-genetic background could reverse cup-5-/- lethality. In this strain, the homozygous lethal deletion of cup-5 is balanced by $d p y-10$ marked translocation ${ }^{43}$. We performed a survival assay by knocking down specific genes in cup-5+/- worms and scoring for lethality (Fig. $4 \mathrm{c}$ and Supplementary Fig S6).

Multidrug resistance protein-4 (MRP-4) is a versatile efflux transporter for drugs, toxins, peptides and lipids and is known to rescue cup-5-/- lethality ${ }^{44}$. It is hypothesized that in the absence of cup-5, mrp-4 mis-localizes in endocytic compartments causing toxicity that is then alleviated upon its knockdown. RNAi knockdown of either catp-6 or catp-5 rescued cup-5-/- lethality favorably compared to mrp-4 knockdown (Supplementary Fig S6).

Knocking down $c l h-6$, another lysosome-resident channel that regulates lumenal chloride, showed no such rescue ${ }^{24,28}$.

Catp-6 facilitates lysosomal $\mathrm{Ca}^{2+}$ accumulation-Given that the rescue of lethality might occur without restoring lysosomal function, we tested whether any of our candidate genes reversed lysosomal phenotypes. Cup- 5 knockdowns show abnormally large lysosomes due to lysosomal storage ${ }^{28}$. We therefore used the hypomorph ar645 with a G401E mutation in cup-5 leading to dysfunction that is insufficient for lethality, yet leads to engorged lysosomes $^{45}$. In the arIs37; cup-5(ar465) strain, soluble GFP that is secreted from the muscle cells into the pseudocoelom is internalized by the coelomocytes and trafficked for degradation to dysfunctional lysosomes ${ }^{45}$. Thus, in these worms, the lysosomes in coelomocytes are abnormally enlarged and labeled with GFP (Fig. 4d).

RNAi knockdowns of catp-6 in these nematodes rescued lysosomal morphology (Fig. 4d-e, Methods). Knocking down either catp-5 or $m r p-4$ showed only a marginal recovery of 
phenotype. Given that mrp-4 is not a lysosome resident protein and its inability rescue the lysosomal phenotype suggests that mechanistically, its rescue of cup-5-/- lethality is likely to be extra lysosomal, consistent with previous hypotheses.

We then checked whether catp-6-mediated rescue of a physical phenotype i.e., lysosome morphology, also led to a restoration of a chemical phenotype, i.e., its lumenal $\mathrm{Ca}^{2+}$. Lysosomal $\mathrm{Ca}^{2+}$ measurements using CalipHluor $_{L y}$ in cup-5+/- nematodes and in catp-6 knockdowns we made. Wild type nematodes showed lysosomal $\mathrm{Ca}^{2+}$ levels of $11 \pm 0.8 \mu \mathrm{M}$ (Fig. 4f-h). In cup- $5+/-$ nematodes lysosomal $\mathrm{Ca}^{2+}$ was elevated to $40 \pm 1.5 \mu \mathrm{M}$, consistent with cup- 5 being a $\mathrm{Ca}^{2+}$ release channel (Fig. $4 \mathrm{f}-\mathrm{h}$ ). Interestingly, catp-6 knockdown restored lysosomal $\mathrm{Ca}^{2+}$ to wild-type levels. Thus catp- 6 function directly opposes that of cup-5 as it rescues cup- 5 deficient phenotypes at three levels - the whole organism in terms of lethality, at the sub-cellular level in terms of lysosome phenotype, at sub-organelle level in terms of its lumenal chemical composition. Cumulatively, these indicate that catp- 6 facilitates lysosomal $\mathrm{Ca}^{2+}$ import. Accordingly, catp-6 deletion led to lysosomal $\mathrm{Ca}^{2+}$ dropping to $1.6 \pm 0.4 \mu \mathrm{M}$, consistent with it facilitating $\mathrm{Ca}^{2+}$ import.

\section{ATP13A2 facilitates lysosomal $\mathrm{Ca}^{2+}$ accumulation.}

Mutations in ATP13A2, the human homolog of catp-6, belong to the PARK9 Parkinsons disease susceptibility locus. These mutations lead to the Kufor- Rakeb syndrome, a severe, early onset, autosomal recessive form of Parkinsons disease with dementia ${ }^{46}$. Parkinsons disease is strongly connected to $\mathrm{Ca}^{2+}$ dysregulation since excessive cytosolic $\mathrm{Ca}^{2+}$ causes excitotoxicity of dopaminergic neurons ${ }^{47}$. Interestingly, overexpressing ATP13A2 suppresses toxicity and reduces cytosolic $\mathrm{Ca}^{2+27,48}$. Further, loss of ATP13A2 function leads to neuronal ceroid lipofuscinosis, a lysosomal storage disorder, implicating the lysosome as its potential site of action ${ }^{49}$.

To confirm whether i.e., ATP13A2, also facilitated lysosomal $\mathrm{Ca}^{2+}$ import, we mapped lysosomal $\mathrm{Ca}^{2+}$ in human fibroblasts. We created a variant called CalipHluor ${ }^{m L y}$ suited to measure the high acidity of mammalian lysosomes (Supplementary Fig. S7a).

CalipHluor ${ }^{m L y}$ showed similar $\mathrm{pH}$ and $\mathrm{Ca}^{2+}$ response characteristics in vitro, on beads and in cellulo and its $\mathrm{Ca}^{2+}$ sensing characteristics are unaffected by the new $\mathrm{pH}$ sensing module (Supplementary Fig. S7b - e)

We then localized CalipHIuor ${ }^{m L y}$ in lysosomes of primary human dermal fibroblasts (HDF cells) obtained from punch-skin biopsies. We showed that CalipHluor $^{m L y}$ labels lysosomes in HDF cells by scavenger receptor mediated endocytosis (Fig. 5a-b Supplementary Fig. S8). Briefly, a $1 \mathrm{~h}$ pulse of $500 \mathrm{nM}$ CalipHluor ${ }^{m L y}$ followed by a $9 \mathrm{~h}$ chase efficiently labels lysosomes in this cell type (Fig. 5a-b).

We then measured lysosomal $\mathrm{Ca}^{2+}$ in fibroblasts from normal individuals and L6025 primary fibroblasts isolated from male patients with Kufor Rakeb syndrome, that are homozygous for a $\mathrm{C}>\mathrm{T}$ mutation in 1550 of ATP13A2 ${ }^{50}$. This mutation results in ATP13A2 being unable to exit the ER and the lysosomes are devoid of ATP13A2 $2^{50}$. After confirming its lysosomal localization in L6025 cells, using CalipHluor $^{m L y}$ we measured lysosomal $\mathrm{pH}$ and $\mathrm{Ca}^{2+}$ (Fig. 5b-d). Lysosomes in KRS patients showed 14-fold lower $\mathrm{Ca}^{2+}$ and $\sim$-fold 
lower $\left[\mathrm{H}^{+}\right]$than normal (Fig. 5c-e) confirming that ATP13A2 mediates lysosomal $\mathrm{Ca}^{2+}$ accumulation.

\section{Conclusion}

Small molecule as well as genetically encodable $\mathrm{Ca}^{2+}$ indicators have profoundly impacted biology. However, their $\mathrm{pH}$ sensitivity has restricted their use to the cytoplasm or the endoplasmic reticulum, where the $\mathrm{pH}$ is neutral and fairly constant. $\mathrm{Ca}^{2+}$ mapping of acidic microenvironments has therefore not been previously possible. Our DNA-based fluorescent reporter, CalipHluor, combines the photophysical advantages of small molecule $\mathrm{Ca}^{2+}$ indicators with the precise organelle targetability of endocytic tracers. CalipHluor is a pHcorrectable $\mathrm{Ca}^{2+}$ reporter that simultaneously reports $\mathrm{pH}$ and $\mathrm{Ca}^{2+}$ in organelles retaining concentration information on both ions with single organelle addressability. Thus, by knowing exactly how the affinity (the $\mathrm{K}_{\mathrm{d}}$ ) of the $\mathrm{Ca}^{2+}$ sensitive probe changes with $\mathrm{pH}$, we compute the $\mathrm{K}_{\mathrm{d}}$ at every pixel in the $\mathrm{pH}$ map to generate a $\mathrm{K}_{\mathrm{d}}$ map. From the $\mathrm{K}_{\mathrm{d}}$ map and the $\mathrm{O} / \mathrm{R}$ map, we can construct the true $\mathrm{Ca}^{2+}$ map of the acidic organelle.

Given the newfound ability to directly quantitate lysosomal $\mathrm{Ca}^{2+}$ using CalipHluor, we identified ATP13A2 - a risk gene for Parkinson's disease - as a potential lysosomal $\mathrm{Ca}^{2+}$ importer. We found that the function of catp-6, the C. elegans homolog of ATP13A2, directly opposed that of a well-known lysosome-resident $\mathrm{Ca}^{2+}$ release channel, cup-5. It reversed cup-5 phenotypes at three different levels - a whole organism phenotype, a subcellular phenotype and an intra-lysosomal phenotype. This now provides a framework to identify more lysosomal $\mathrm{Ca}^{2+}$ regulators.

The ability to map $\mathrm{pH}$ and $\mathrm{Ca}^{2+}$ with single organelle addressability is critical to discriminate between lysosomal hypo-acidification and $\mathrm{Ca}^{2+}$ dysregulation. CalipHluor can be used to map lumenal $\mathrm{Ca}^{2+}$ changes in diverse organelles. There is already a range of DNA-based pH sensors specifically suited to organelles like the Golgi, the recycling endosome and the ER 19,20,22-24. Given the array of small molecule $\mathrm{Ca}^{2+}$ indicators covering various $\mathrm{Ca}^{2+}$ affinities, this positions CalipHluor technology to deliver new insights into organellar $\mathrm{Ca}^{2+}$ regulation.

\section{Online Methods}

\section{Preparation of BAPTA-5F aldehyde (1)}

BAPTA-5F aldehyde (1) was synthesized according to previous reported procedure 51,52 . $\mathrm{POCl}_{3}(1.12 \mathrm{~g}, 7.3 \mathrm{mmol})$ was added to DMF $(5 \mathrm{~mL})$ at $0{ }^{\circ} \mathrm{C}$ and allowed to stir for $10 \mathrm{~min}$. After $10 \mathrm{~min}$, BAPTA-5F (1.6 g, $2.9 \mathrm{mmol})$ in DMF ( $3 \mathrm{~mL})$ was added to above solution and heated to $65^{\circ} \mathrm{C}$. After completion of the reaction, reaction mixture was poured in water and $\mathrm{pH}$ adjusted to 6.0 by adding aq. $\mathrm{NaOH}(1 \mathrm{M})$ solution. Product was extracted with ethylacetate $(3 \times 50 \mathrm{~mL})$ and solvent was evaporated. Crude product was purified by column chromatography on silica gel using hexane/EtOAc (70/30 to 60/40) as an eluent to obtain BAPTA-5F aldehyde (1) in $65 \%$ yield. ${ }^{1} \mathrm{H}-\mathrm{NMR}\left(500 \mathrm{MHz}, \mathrm{CDCl}_{3}\right) \delta_{p p m} 9.80(\mathrm{~s}, 1 \mathrm{H})$, $7.30-7.45(\mathrm{~m}, 2 \mathrm{H}), 6.83(\mathrm{t}, 1 \mathrm{H}, J=7 \mathrm{~Hz}), 6.76(\mathrm{~d}, 1 \mathrm{H}, J=8 \mathrm{~Hz}), 6.59$ (t, 2H, $J=8 \mathrm{~Hz}), 4.40$ (t, $2 \mathrm{H}, J=7.0 \mathrm{~Hz}), 4.35(\mathrm{t}, 2 \mathrm{H}, J=7.5 \mathrm{~Hz}), 4.33(\mathrm{~s}, 4 \mathrm{H}), 4.22(\mathrm{~s}, 4 \mathrm{H}), 3.59$ (s, 6H), 3.57 (s, 
6H). ${ }^{13} \mathrm{C}-\mathrm{NMR}\left(125 \mathrm{MHz}, \mathrm{CDCl}_{3}\right) \delta_{p p m} 190.5,171.8,171.2,159.4,157.5,151.4,151.3$, 149.6, 145.1, 135.6, 135.5, 130.0, 126.9, 120.3, 120.2, 116.6, 110.8, 107.3, 107.1, 101.3, 101.1, 67.1, 67.0, 53.5, 53.4, 51.9, 51.7. HRMS (ESI) $\mathrm{m} / \mathrm{z}$. $[\mathrm{M}]^{+}$calcd for $\mathrm{C}_{27} \mathrm{H}_{31} \mathrm{FN}_{2} \mathrm{O}_{11}{ }^{+}$ 578.1912, found: 578.1927.

\section{Synthesis of Rhod-5F}

To a solution of BAPTA-5F aldehyde (1) $(50 \mathrm{mg}, 0.086 \mathrm{mmol})$ in propionic acid (4 mL), 3(dimethylamino) phenol (26 mg, $0.19 \mathrm{mmol}$ ) and p-Toluenesulfonic acid (p-TSA) (1.5 mg, $0.009 \mathrm{mmol}$ ) were added and allowed to stir at room temperature for $12 \mathrm{~h}$. After $12 \mathrm{~h}$, Chloranil (21 mg, $0.086 \mathrm{mmol}$ ) in DCM (3 mL) was added to above reaction mixture and allowed to stir at room temperature overnight. After completion of the reaction, the crude product was extracted with DCM $(3 \times 30 \mathrm{~mL})$. The crude product was then purified by column chromatography on silica gel using DCM/Methanol (95/5 to 90/10 \%) as an eluent to obtain methyl ester of Rhod-5F as a dark red solid in $35 \%$ yield. LCMS (ESI) $\mathrm{m} / z$. [M] ${ }^{+}$ calcd for $\mathrm{C}_{43} \mathrm{H}_{48} \mathrm{FN}_{4} \mathrm{O}_{11}+815.3298$, found: 815.5. Methyl ester of Rhod-5F (5 mg, 0.006 $\mathrm{mmol})$ was dissolved in methanol and water mixture $(1: 0.5 \mathrm{~mL})$, to which $\mathrm{KOH}(3.5 \mathrm{mg}$, $0.063 \mathrm{mmol}$ ) was added and allowed to stir for $8 \mathrm{~h}$ at room temperature. After completion of the reaction, solution $\mathrm{pH}$ was adjusted to 6.0 and crude product was extracted with DCM $(3 \times 5 \mathrm{~mL})$. Product was purified by HPLC (50:50 acetonitrile/water, $0.1 \%$ TFA) to obtained Rhod-5F. LCMS (ESI) $\mathrm{m} / z$. [M] ${ }^{+}$calcd for $\mathrm{C}_{39} \mathrm{H}_{40} \mathrm{FN}_{4} \mathrm{O}_{11}+759.2672$, found: 759.4.

\section{Preparation of 1-azido-3-iodopropane (2)}

To a solution of 1-bromo-3-chloropropane (1 g, $6.4 \mathrm{mmol})$ in DMSO $(8 \mathrm{~mL})$, sodium azide $(0.5 \mathrm{~g}, 7.7 \mathrm{mmol})$ was added and allowed to stir at room temperature for $12 \mathrm{~h}$. After completion of the reaction, the mixture was diluted with water and the product was extracted with hexane to obtain 1-azido-3-chloropropane. Sodium iodide $(1.5 \mathrm{~g}, 10 \mathrm{mmol})$ was then added to a solution of 1-azido3-chloropropane $(1 \mathrm{~g}, 8.4 \mathrm{mmol})$ in acetone $(25 \mathrm{~mL})$ and allowed to stir at room temperature for $8 \mathrm{~h}$. After completion of the reaction, the solvent was evaporated under vacuum. The crude product was diluted with a saturated solution of $\mathrm{Na}_{2} \mathrm{~S}_{2} \mathrm{O}_{3}$ to quench the unreacted iodine followed by extraction of the compound with ethyl acetate $(3 \times 50 \mathrm{~mL})$. This was dried over $\mathrm{Na}_{2} \mathrm{SO}_{4}$ and the product 1-azido-3-iodopropane (2) was used for further reactions without purification.

\section{Preparation of 3-((3-azidopropyl)(methyl)amino)phenol (3)}

To a solution of 3-aminophenol ( $1 \mathrm{~g}, 9.2 \mathrm{mmol})$ in acetone $(30 \mathrm{~mL})$, potassium carbonate $(2.5 \mathrm{~g}, 18.4 \mathrm{mmol})$ was added and allowed to stir at room temperature for $20 \mathrm{~min}$. After 20 min, iodomethane $(1.3 \mathrm{~g}, 9.2 \mathrm{mmol})$ was added and the mixture was further stirred for $8 \mathrm{~h}$ at room temperature. After completion of reaction, the solvent was evaporated and the crude product was extracted with DCM $(3 \times 30 \mathrm{~mL})$. This was followed by purification of the crude product by column chromatography on silica gel using hexane/ethyl acetate $(80 / 20 \%)$ as an eluent to obtained 3-(methylamino) phenol in $45 \%$ yield.

To a solution of 3-(methylamino) phenol (1 g, $8.1 \mathrm{mmol})$ in DMF $(8 \mathrm{~mL}), \mathrm{N}, \mathrm{N}-$ Diisopropylethylamine $(1.26 \mathrm{~g}, 9.7 \mathrm{mmol})$ was added and stirred for $20 \mathrm{~min}$ at room temperature. After $20 \mathrm{~min}$, 1-azido-3-iodopropane (2) (1.7 g, $8.1 \mathrm{mmol}$ ) was added to above 
reaction mixture and heated at $65{ }^{\circ} \mathrm{C}$ for $8 \mathrm{~h}$. After completion of the reaction, the solvent was evaporated and the crude product was extracted with diethylether $(3 \times 40 \mathrm{~mL})$. Then, the crude product was purified by column chromatography on silica gel using hexane/ethyl acetate $(90 / 10 \%)$ as an eluent to obtained 3-((3-azidopropyl)(methyl)amino)phenol (3) liquid in $72 \%$ yield. ${ }^{1} \mathrm{H}-\mathrm{NMR}\left(500 \mathrm{MHz}, \mathrm{CDCl}_{3}\right) \delta_{p p m} 7.09-7.13(\mathrm{~m}, 1 \mathrm{H}), 6.3(\mathrm{~d}, 1 \mathrm{H}, J=$ $7.5 \mathrm{~Hz}), 6.21(\mathrm{dd}, 2 \mathrm{H}, J=2 \mathrm{~Hz}, 8.5 \mathrm{~Hz}), 3.42(\mathrm{t}, 2 \mathrm{H}, J=6.5 \mathrm{~Hz}), 3.38(\mathrm{t}, 2 \mathrm{H}, J=7 \mathrm{~Hz}), 2.94$ $(\mathrm{s}, 3 \mathrm{H}), 1.87$ (t, $2 \mathrm{H}, J=6.5 \mathrm{~Hz}) .{ }^{13} \mathrm{C}-\mathrm{NMR}\left(125 \mathrm{MHz}, \mathrm{CDCl}_{3}\right) \delta_{p p m} 156.7,150.7,130.2$, 105.1, 103.5, 99.3, 49.8, 49.2, 38.6, 26.3. HRMS (ESI) $\mathrm{m} / z$. $[\mathrm{M}]^{+}$calcd for $\mathrm{C}_{10} \mathrm{H}_{14} \mathrm{~N}_{4} \mathrm{O}^{+}$ 206.1168, found:206.1177

\section{Preparation of Rhod-5F-OMe (4)}

To a solution of BAPTA-5F aldehyde (1) $(50 \mathrm{mg}, 0.086 \mathrm{mmol})$ in propionic acid $(4 \mathrm{~mL})$, 3-((3-azidopropyl)(methyl)amino)phenol (3) $(40 \mathrm{mg}, 0.19 \mathrm{mmol})$ and p-Toluenesulfonic acid (p-TSA) $(1.5 \mathrm{mg}, 0.009 \mathrm{mmol})$ were added and allowed to stir at room temperature for $12 \mathrm{~h}$. After $12 \mathrm{~h}$, Chloranil (21 mg, $0.086 \mathrm{mmol})$ in DCM (3 mL) was added to above reaction mixture and allowed to stir at room temperature overnight. After completion of the reaction, the solvent was evaporated and the crude product was extracted with DCM $(3 \times 20$ $\mathrm{mL}$ ). The crude product was then purified by column chromatography on silica gel using DCM/Methanol (95/5 to 90/10\%) as an eluent to obtain Rhod-5F-OMe (4) as a dark red solid in $30 \%$ yield. ${ }^{1} \mathrm{H}-\mathrm{NMR}\left(500 \mathrm{MHz}, \mathrm{DMSO}-\mathrm{d}_{6}\right) \delta_{p p m} 7.55(\mathrm{~d}, 2 \mathrm{H}, J=8 \mathrm{~Hz}), 7.15-7.16$ (m, 3H), 7.00-7.04 (m, 3H), 6.88 (dd, 2H, $J=3 \mathrm{~Hz}, 9 \mathrm{~Hz}), 6.75$ (dd, $1 \mathrm{H}, J=6 \mathrm{~Hz}, 9 \mathrm{~Hz}$ ), $6.65(\mathrm{td}, 1 \mathrm{H}, J=3 \mathrm{~Hz}, 6 \mathrm{~Hz}), 4.20-4.30(\mathrm{~m}, 8 \mathrm{H}), 4.02$ (s, 4H), 3.71 (t, 4H, $J=7 \mathrm{~Hz}), 3.53$ (s, $6 \mathrm{H}), 3.47$ (s, 10H), $3.25(\mathrm{~s}, 6 \mathrm{H}), 1.88(\mathrm{q}, 4 \mathrm{H}, J=7 \mathrm{~Hz}) .{ }^{13} \mathrm{C}-\mathrm{NMR}(125 \mathrm{MHz}$, DMSO-d 6 ) $\delta_{p p m} 171.2,171.1,158.3,157.3,156.4,156.1,140.7,135.2,135.1,131.9,123.6,123.1$, 119.1, 116.8, 114.9, 114.4, 106.4, 106.2, 101.2, 101.0, 96.4, 67.3, 67.2, 54.9, 53.2, 53.0, 51.5, 51.2, 49.7, 48.6, 48.1, 26.0, 22.1. HRMS (ESI) $\mathrm{m} / \mathrm{z}$. [M] ${ }^{+}$calcd for $\mathrm{C}_{47} \mathrm{H}_{54} \mathrm{FN}_{10} \mathrm{O}_{11}{ }^{+}$ 953.3952, found: 953.3967.

\section{Preparation of Rhod-5F- $\mathrm{N}_{3}$}

Rhod-5F-OMe (4) (5 mg, $0.005 \mathrm{mmol})$ was dissolved in methanol and water mixture (1:0.5 $\mathrm{mL})$, to which $\mathrm{KOH}(3.5 \mathrm{mg}, 0.063 \mathrm{mmol})$ was added and allowed to stir for $8 \mathrm{~h}$ at room temperature. After completion of the reaction, solution $\mathrm{pH}$ was adjusted to 6.0 and crude product was extracted with DCM $(3 \times 5 \mathrm{~mL})$. Product was purified by HPLC (50:50 acetonitrile/water, $0.1 \%$ TFA). LCMS (ESI) $\mathrm{m} / \mathrm{z}$. [M] ${ }^{+}$calcd for $\mathrm{C}_{43} \mathrm{H}_{46} \mathrm{FN}_{10} \mathrm{O}_{11}{ }^{+}$ 897.3326, found: 897.5.

\section{Reagents}

All the chemicals used for the synthesis of Rhod-5F-N ${ }_{3}$ were purchased from Sigma (USA) and Alfa Aesar (USA). ${ }^{1} \mathrm{H}-\mathrm{NMR}$ and ${ }^{13} \mathrm{C}-\mathrm{NMR}$ were recorded on Bruker AVANCE II+, $500 \mathrm{MHz}$ NMR spectrophotometer in $\mathrm{CDCl}_{3}$ and DMSO- $\mathrm{d}_{6}$ and tetramethylsilane (TMS) used as an internal stranded. Mass spectra were recorded in Agilent 6224 Accurate-Mass TOF LC/MS.

All fluorescently labeled oligonucleotides were purchased from IDT (USA) and IBA-GmBh (Germany). HPLC purified oligonucleotides were dissolved in Milli-Q water to make 100 
$\mu \mathrm{M}$ stock solutions and quantified using UV-spectrophotometer and stored at $-20{ }^{\circ} \mathrm{C}$. Ethylene glycol-bis( $\beta$-aminoethyl ether)-N,N,N,N -tetraacetic acid (EGTA), ampicillin, carbencillin, isopropyl $\beta$-D-1-thiogalactopyranoside (IPTG), nigericin and monensin were purchased from Sigma (USA) and ionomycin was obtained from Cayman chemical (USA). Maleylated BSA (mBSA) was maleylated according to a previously published protocol ${ }^{20}$. Monodisperse Silica Microspheres were obtained from Cospheric (USA).

\section{Rhod-5F conjugation and sample preparation}

Rhod-5F was first conjugated to D2 and O3-DBCO strands. Rhod-5F-N 3 ( $25 \mu \mathrm{M})$ was added to $5 \mu \mathrm{M}$ of dibenzocyclooctyne (DBCO) labelled $\mathrm{D} 2$ strand in $100 \mu \mathrm{L}$ of sodium phosphate $(10 \mathrm{mM})$ buffer containing $\mathrm{KCl}(100 \mathrm{mM})$ at $\mathrm{pH} 7.0$ and allowed to stir overnight at room temperature. After completion of the reaction, $10 \mu \mathrm{L}$ of $3 \mathrm{M}$ sodium acetate ( $\mathrm{pH} 5.5$ ) and $250 \mu \mathrm{L}$ of ethanol were added to reaction mixture and kept overnight at $-20^{\circ} \mathrm{C}$ for DNA precipitation ${ }^{53}$. Then, the reaction mixture was centrifuged at $14000 \mathrm{rpm}$ at $4{ }^{\circ} \mathrm{C}$ for $20 \mathrm{~min}$ to remove the unreacted Rhod-5F-N 3 and the precipitate was resuspended in ethanol and centrifuged. This procedure was repeated 3 times for complete removal of unreacted Rhod-5F-N 3 . Rhod-5F conjugation was confirmed by gel electrophoresis by running a native polyacrylamide gel containing 15\% (19:1 acrylamide/bis-acrylaimde) in 1X TBE buffer [Tris. $\mathrm{HCl}(100 \mathrm{mM})$, boric acid $(89 \mathrm{mM})$ and EDTA $(2 \mathrm{mM}), \mathrm{pH}$ 8.3]. The same protocol was used for the conjugation of Rhod-5F-N $\mathrm{N}_{3}$ to $\mathrm{O} 3-\mathrm{DBCO}$.

To prepare a CalipHluor $_{L y}$ and CalipHluor ${ }^{m L y}$ sample, $5 \mu \mathrm{M}$ of D1 or OG-D1 and $5 \mu \mathrm{M}$ of Rhod-5F conjugated D2 strands were mixed in equimolar ratios in $10 \mathrm{mM}$ sodium phosphate buffer ( $\mathrm{pH} 7.2$ ) containing $100 \mathrm{mM}$ of $\mathrm{KCl}$. The resultant solution was heated to $90{ }^{\circ} \mathrm{C}$ for $15 \mathrm{~min}$, cooled to room temperature at $5{ }^{\circ} \mathrm{C}$ per $15 \mathrm{~min}$ and kept at $4{ }^{\circ} \mathrm{C}$ for overnight ${ }^{20}$. For CalipHluor, $5 \mu \mathrm{M}$ of O1-A488, $5 \mu \mathrm{M}$ of O2-A647 and $5 \mu \mathrm{M}$ of Rhod-5F conjugated $\mathrm{O} 3$ strands were mixed in equimolar ratios in $10 \mathrm{mM}$ sodium phosphate buffer at pH 5.5 containing $100 \mathrm{mM}$ of $\mathrm{KCl}$. Solution was heated to $90{ }^{\circ} \mathrm{C}$ for $15 \mathrm{~min}$, then cooled to room temperature at $3{ }^{\circ} \mathrm{C}$ per $15 \mathrm{~min}$ and kept at $4 \mathrm{C}$ for overnight. See table $\mathrm{S} 1$ for sequence information.

\section{In vitro fluorescence measurements}

Fluorescence spectra were measured on a FluoroMax-4 spectrophotometer (Horiba Scientific, Edison, NJ, USA) using previously established protocols ${ }^{20}$. For in vitro $\mathrm{pH}$ measurements, CalipHluor $_{L y}$ sample was diluted to $30 \mathrm{nM}$ in $\mathrm{pH}$ clamping buffer $\left[\mathrm{CaCl}_{2}(50\right.$ $\mu \mathrm{M}$ to $10 \mathrm{mM})$, HEPES $(10 \mathrm{mM})$, MES $(10 \mathrm{mM})$, sodium acetate $(10 \mathrm{mM})$, EGTA $(10 \mathrm{mM})$, $\mathrm{KCl}(140 \mathrm{mM}), \mathrm{NaCl}(5 \mathrm{mM})$ and $\left.\mathrm{MgCl}_{2}(1 \mathrm{mM})\right]$ of desired $\mathrm{pH}$ and equilibrated for $30 \mathrm{~min}$ at room temperature. All the samples were excited at $495 \mathrm{~nm}$ and emission spectra was collected from $505 \mathrm{~nm}$ to $750 \mathrm{~nm}$. The ratio of donor (D) emission intensity at $520 \mathrm{~nm}$ to acceptor (A) emission intensity at $665 \mathrm{~nm}$ was plotted as a function of $\mathrm{pH}$ to generate the $\mathrm{pH}$ calibration curve. Mean of D/A from two independent experiments and their s.e.m were plotted for each $\mathrm{pH}$. Fold change in D/A of CalipHluor ${ }_{L y}$ was calculated from the ratios of D/A at $\mathrm{pH} 4.0$ and $\mathrm{pH}$ 6.5. $\mathrm{pH}_{1 / 2}$ of CalipHluor ${ }_{L y}$ at different $\left[\mathrm{Ca}^{2+}\right.$ ] values were derived from $\mathrm{pH}$ calibration curve by fitting to Boltzmann sigmoid. 
For in vitro $\left[\mathrm{Ca}^{2+}\right]$ measurements, CalipHluor ${ }_{L y}$ sample was diluted to $30 \mathrm{nM}$ in $\mathrm{Ca}^{2+}$ clamping buffer [HEPES $(10 \mathrm{mM})$, MES $(10 \mathrm{mM})$, sodium acetate $(10 \mathrm{mM})$, EGTA $(10$ $\mathrm{mM}), \mathrm{KCl}(140 \mathrm{mM}), \mathrm{NaCl}(5 \mathrm{mM})$ and $\left.\mathrm{MgCl}_{2}(1 \mathrm{mM})\right]$. We then varied the amount of $\left[\mathrm{Ca}^{2+}\right]$ from $0 \mathrm{mM}$ to $20 \mathrm{mM}$ and adjusted to different $\mathrm{pH}$ values (4.5-7.20). The amount of free $\left[\mathrm{Ca}^{2+}\right]$ at a given $\mathrm{pH}$ was calculated based on Maxchelator software (http:// maxchelator.stanford.edu/). Rhod-5F and Alexa 647 were excited at $545 \mathrm{~nm}$ and $630 \mathrm{~nm}$ respectively. Emission spectra for Rhod-5F (O) and Alexa 647 (R) were collected from 570$620 \mathrm{~nm}$ and $660-750 \mathrm{~nm}$ respectively. Mean of O/R from two independent experiments and their s.e.m were plotted for each $\left[\mathrm{Ca}^{2+}\right]$. Similar experiments were performed with $50 \mathrm{nM}$ CalipHluor $^{m L y}$ at $\mathrm{pH} 4.6$ and $\mathrm{pH}$ 5.1. In vitro calcium binding affinity $\left(K_{\mathrm{d}}\right)$ of Rhod-5F was obtained by plotting ratios of Rhod-5F (O) emission intensity at $580 \mathrm{~nm}$ to Alexa $647(\mathrm{R})$ emission intensity at $665 \mathrm{~nm}$ as a function of free $\left[\mathrm{Ca}^{2+}\right]$ and fitted using sigmoidal growth Hill1 equation.

$$
\mathrm{Y}=S+(E-S) \times\left(X^{n} /\left(K_{d}^{n}+X^{n}\right)\right)
$$

$\mathrm{X}$ is free $\left[\mathrm{Ca}^{2+}\right], \mathrm{Y}$ is $\mathrm{O} / \mathrm{R}$ ratio at given free $\left[\mathrm{Ca}^{2+}\right], \mathrm{S}$ is $\mathrm{O} / \mathrm{R}$ ratio at low $\left[\mathrm{Ca}^{2+}\right], \mathrm{E}$ is $\mathrm{O} / \mathrm{R}$ ratio at high $\left[\mathrm{Ca}^{2+}\right], K_{\mathrm{d}}$ is dissociation constant and $\mathrm{n}$ is Hill coefficient. Fold change response in $\mathrm{O} / \mathrm{R}$ of CalipHluor $_{L y}$ was calculated from ratio of $\mathrm{O} / \mathrm{R}$ at high $\left[\mathrm{Ca}^{2+}\right]$ and $\mathrm{O} / \mathrm{R}$ at low $\left[\mathrm{Ca}^{2+}\right]$.

\section{C.elegans methods and strains}

Standard methods were followed for the maintenance of $C$. elegans ${ }^{54}$. Wild type strain used was the $C$. elegans isolate from Bristol, strain N2 (Brenner, 1974). Strains used in the study, provided by the Caenorhabditis Genetics Center (CGC), are RRID:WB-STRAIN:RB2510 W08D2.5(ok3473) and RRID:WBSTRAIN:VC1242 [+/mT1 II; cup-5(ok1698)/mT1 [dpy-10(e128)] III]. Transgenics used in this study, also provided by the CGC, are RRID:WB-STRAIN:NP1129 cdIs131 [pcc1::GFP::rab-5 + unc-119(+) + myo-2p::GFP], a transgenic strain that express GFP-fused early endosomal marker RAB-5 inside coelomocytes, RRID:WB-STRAIN:NP871 cdIs66 [pcc1::GFP::rab-7 + unc-119(+) + myo-2p::GFP], a transgenic strain that express GFP-fused late endosomal / lysosomal marker RAB-7 inside coelomocytes RRID:WB-STRAIN:RT258 pwIs50 [Imp-1::GFP+ Cbr-unc-119(+)], a transgenic strain expressing GFP-tagged lysosomal marker LMP-1 and arIs37[myo-3p::ssGFP + dpy-2O(+)]I, a transgenic strain that express ssGFP in the body muscles which secreted in pseudocoelom and endocytosed by coelomocytes and arIs37[myo-3p::ssGFP + dpy-20(+)]Icup5(ar465) a transgenic strain with enlarged GFP containing vesicles in coelomocytes due to defective degradation. Gene knocked down was performed using Ahringer library-based RNAi methods ${ }^{55}$. The RNAi clones used were: L4440 empty vector control, catp-6 (W08D2.5, Ahringer Library), catp-5 (K07E3.7, Ahringer Library) and mrp-4 (F21G4.2, Ahringer Library).

\section{CalipHluor trafficking in coelomocytes}

CalipHluor trafficking in coelomocytes was done in transgenic strains expressing endosomal markers such as GFP::RAB-5 (EE), GFP::RAB-7 (LE) and LMP-1::GFP (Ly) as described 
previously by our lab ${ }^{21}$. Briefly, worms were injected with CalipHluor $_{A 647}(500 \mathrm{nM})$ and incubated for specific time points and transferred on to ice. Worms were anaesthetized using $40 \mathrm{mM}$ of sodium azide in M9 solution. Worms were then imaged on Leica TCS SP5 II STED laser scanning confocal microscope (Leica Microsystems, Inc., Buffalo Grove, IL) using an Argon ion laser for $488 \mathrm{~nm}$ excitation and He-Ne laser for 633nm excitations with a set of filters suitable for GFP and Alexa 647 respectively. Colocalization of GFP and CalipHluor $_{A 647}$ was determined by counting the number CalipHluor $_{A 647}$ positive puncta that colocalize with GFP-positive puncta and quantified as a percentage of total number of CalipHluor $_{A 647}$ positive puncta ${ }^{21}$. In order to confirm lysosomal labeling in a given genetic background, the same procedure was performed on the relevant mutant or RNAi knockdown in pwIs50 [Imp-1::GFP + Cb-unc-119(+)].

\section{RNAi experiments}

Bacteria from the Ahringer RNAi library expressing dsRNA against the relevant gene was fed to worms, and measurements were carried out in one-day old adults of the F1 progeny (Kamath and Ahringer, 2003). RNA knockdown was confirmed by probing mRNA levels of the candidate gene, assayed by RT-PCR. Briefly, total RNA was isolated using the Trizolchloroform method; $2.5 \mu \mathrm{g}$ of total RNA was converted to cDNA using oligo-dT primers. 5 $\mu \mathrm{L}$ of the RT reaction was used to set up a PCR using gene-specific primers. Actin mRNA was used as a control. PCR products were separated on a 1.5\% agarose-TAE gel.

\section{Image acquisition}

Image acquisition was carried out on wide field IX83 inverted microscope (Olympus Corporation of the Americas, Center Valley, PA, USA) using a 60X, 1.42 NA, phase contrast oil immersion objective (PLAPON, Olympus Corporation of the Americas, Center Valley, PA, USA) and Evolve Delta 512 EMCCD camera (Photometrics, USA). Filter wheel, shutter and CCD camera were controlled using Metamorph Premier Ver 7.8.12.0 (Molecular Devices, LLC, USA), suitable for the fluorophores used. Images on the same day were acquired under the same acquisition settings. Alexa 488 channel images (D) were obtained using 480/20 band pass excitation filter, 520/40 band pass emission filter and 89016-ETFITC/Cy3/Cy5 dichroic filter. Alexa 647 channel images (A) were obtained using 640/30 band pass excitation filter, 705/72 band pass emission filter and 89016ET-FITC/Cy3/Cy5 dichroic filter. FRET channel images were obtained using the 480/20 band pass excitation filter, 705/72 band pass emission filter and 89016-ET-FITC/Cy3/Cy5 dichroic filter. Rhod-5F channel images $(\mathrm{O})$ were obtained using 545/25 band pass excitation filter, 595/50 band pass emission filter and a 89016-ET-FITC/Cy3/Cy5 dichroic filter. Confocal images were acquired on a Leica TCS SP5 II STED laser scanning confocal microscope (Leica Microsystems, Inc., Buffalo Grove, IL, USA) equipped with 63X, 1.4 NA, oil immersion objective. Alexa 488 was excited using an Argon ion laser for $488 \mathrm{~nm}$ excitation, Alexa 647 using He-Ne laser for 633 excitation and Rhod-5F using DPSS laser for $561 \mathrm{~nm}$ excitation with a set of dichroics, excitation, and emission filters suitable for each fluorophore.

\section{Image analysis}

Image analysis for quantification of $\mathrm{pH}$ and calcium in single endosomes was done using custom MATLAB code. For each cell the most focused plane was manually selected in the 
Alexa 647 channel. This image and corresponding images from the same z-position in other channels were input into the program. Images from the different channels were then aligned using Enhanced Cross Correlation Optimization ${ }^{56}$. To determine the location of the endosome first a low threshold was used to select the entire cell. Only the area within the cell was subsequently considered for endosome selection. Regions of interest corresponding to individual endosomes were selected in the Alexa 647 channel by adaptive thresholding using Sauvolas method ${ }^{57}$. The initial selection was further refined by watershed segmentation and size filtering. After segmentation regions of interest were inspected in each image and selection errors were corrected manually. Using the cell boundary annular region 10 pixels wide around the cell was selected and used to calculate a background intensity in each image. Then, we measured the mean fluorescence intensity in each endosome in donor (D), acceptor (A), Rhod-5F (O) and Alexa 647 (R) channels and the background intensity corresponding to that cell and channel was subtracted. The two ratios of intensities (D/A and O/R) were then computed for each endosome. Mean D/A of each distribution was plotted as a function of $\mathrm{pH}$ and obtained the in vivo $\mathrm{pH}$ calibration curve. Mean $\mathrm{O} / \mathrm{R}$ of each distribution was plotted as a function of free $\left[\mathrm{Ca}^{2+}\right]$ to generate the in vivo $\mathrm{Ca}^{2+}$ calibration curve. Pseudo color $\mathrm{pH}$ and $\mathrm{Ca}^{2+}$ images were obtained by measuring the $\mathrm{D} / \mathrm{A}$ and $\mathrm{O} / \mathrm{R}$ ratio per pixel, respectively.

\section{In vivo measurements of $\mathrm{pH}$ and $\left[\mathrm{Ca}^{2+}\right]$}

In vivo $\mathrm{pH}$ calibration experiments of CalipHluor ${ }_{L y}$ were carried out using protocols previously established in our lab (Modi et al., 2009; Surana et al., 2011). Briefly, CalipHluor $_{L y}(500 \mathrm{nM})$ was microinjected in pseudocoelom of young adult worms on the opposite side of the vulva. After microinjections, worms were incubated at $22{ }^{\circ} \mathrm{C}$ for $2 \mathrm{~h}$ for maximum labelling of coelomocyte lysosomes. Then, worms were immersed in clamping buffer $\left[\mathrm{CaCl}_{2}(50 \mu \mathrm{M}\right.$ to $10 \mathrm{mM})$, HEPES $(10 \mathrm{mM})$, MES $(10 \mathrm{mM})$, sodium acetate (10 $\mathrm{mM})$, EGTA $(10 \mathrm{mM}), \mathrm{KCl}(140 \mathrm{mM}), \mathrm{NaCl}(5 \mathrm{mM})$ and $\left.\mathrm{MgCl}_{2}(1 \mathrm{mM})\right]$ of desired $\mathrm{pH}$ solutions containing the ionophores nigericin $(50 \mu \mathrm{M})$, monensin $(50 \mu \mathrm{M})$ and ionomycin $(20 \mu \mathrm{M})$. Worm cuticle was perforated to facilitate the entry of buffer in to the body. After 75 min of incubations in clamping buffer, coelomocytes were imaged using wide-field microscopy. Three independent measurements, each with 10 worms, were made for each $\mathrm{pH}$ value.

$\mathrm{Ca}^{2+}$ clamping measurements were carried out using CalipHluor ${ }_{L y}$. Worms were injected with CalipHluor ${ }_{L y}(500 \mathrm{nM})$ and incubated at $22{ }^{\circ} \mathrm{C}$ for $2 \mathrm{~h}$. After $2 \mathrm{~h}$, worms were immersed in $\mathrm{Ca}^{2+}$ clamping buffer [HEPES $(10 \mathrm{mM})$, MES $(10 \mathrm{mM})$, sodium acetate (10 $\mathrm{mM})$, EGTA $(10 \mathrm{mM}), \mathrm{KCl}(140 \mathrm{mM}), \mathrm{NaCl}(5 \mathrm{mM})$ and $\left.\mathrm{MgCl}_{2}(1 \mathrm{mM})\right]$ by varying amount of free $\left[\mathrm{Ca}^{2+}\right]$ from $1 \mu \mathrm{M}$ to $10 \mathrm{mM}$ and adjusted to different $\mathrm{pH}$ values (5.3-6.5). Three independent measurements, each with 10 worms, were made for $\mathrm{Ca}^{2+}$ value.

Early endosome and late endosome $\mathrm{pH}$ and free $\left[\mathrm{Ca}^{2+}\right]$ measurements were carried out using CalipHluor, and lysosomal $\mathrm{pH}$ and free $\left[\mathrm{Ca}^{2+}\right]$ measurements were carried out using CalipHluor $_{L y}$. For real time $\mathrm{pH}$ and $\left[\mathrm{Ca}^{2+}\right]$ measurements, 10 hermaphrodites were injected with $500 \mathrm{nM}$ of CalipHluor and CalipHluor ${ }_{L y}$ for EE, LE and Ly respectively and incubated for the indicated time points (EE (5 min), LE (17 min) and Ly (60 min)). Worms were 
anaesthetized using $40 \mathrm{mM}$ of sodium azide in M9 solution and imaged on wide field microscopy. Image analysis was carried out using custom MATLAB code as described in image analysis.

\section{Calculating pH corrected $\left[\mathrm{Ca}^{2+}\right]$ in EE, LE and Ly}

The D/A and O/R ratios in Ly, LE and EE were measured using CalipHluor ${ }_{L y}$ and CalipHluor as mentioned above at single endosome resolution. Over 100 endosomes were analyzed in each measurement in worms to generate a Gaussian spread of D/A. Around $\sim 5 \%$, endosomes which fell outside the range of Mean \pm 2 S.D (S.D = standard deviation) which was set as a threshold for our measurements in EE, LE and Ly. To get $\mathrm{pH}$ corrected $\left[\mathrm{Ca}^{2+}\right]$ values, we measured the $\mathrm{pH}$ value in each individual endosome with single endosome resolution from their $\mathrm{D} / \mathrm{A}$ ratios. $\mathrm{pH}$ values in endosomes were calculated using equation (2) which was derived from our in vivo $\mathrm{pH}$ calibration curve,

$$
\mathrm{pH}=p H_{1 / 2}+\left[0.3 \ln \left(\left(\frac{K_{1}-K_{2}}{Y-K_{2}}\right)-1\right)\right]
$$

$\mathrm{K}_{1}, \mathrm{~K}_{2}$ and $\mathrm{pH}_{1 / 2}$ represent parameters derived from a Boltzmann fit of the in vivo $\mathrm{pH}$ calibration curve, and $\mathrm{Y}$ represents the $\mathrm{D} / \mathrm{A}$ ratio in a given endosome.

Next, the $\mathrm{K}_{\mathrm{d}}$ of CalipHluor $_{L y}$ and fold change response in O/R ratios of CalipHluor ${ }_{L y}$ from low $\left[\mathrm{Ca}^{2+}\right] \mathrm{O} / \mathrm{R}$ to high $\left[\mathrm{Ca}^{2+}\right]$ were obtained as functions of $\mathrm{pH}$. The in vitro and in vivo $\mathrm{K}_{\mathrm{d}}$ were measured at different $\mathrm{pH}$ points ranging from 4.5 to 7.2 by fitting $\mathrm{Ca}^{2+}$ calibration curves by fitting to the Hill equation (1). From in vitro and in vivo $\left[\mathrm{Ca}^{2+}\right]$ calibration curves, the $\mathrm{K}_{\mathrm{d}}$ of CalipHluor $\mathrm{L}_{\mathrm{L}}$ was plotted as a function of $\mathrm{pH}$ using following equation,

$$
\mathrm{K}_{\mathrm{d}}=1.03+5.14 \times 10^{12} \times e^{\left(-\frac{p H}{0.189}\right)}+3.108 \times 10^{6} \times e^{\left(-\frac{p H}{0.412}\right)}
$$

By using equation, we can deduce $\mathrm{K}_{\mathrm{d}}$ of CalipHluor $_{L y}$ at any given $\mathrm{pH}$ in EE, LE and Ly. $\mathrm{O} / \mathrm{R}_{\max }$ (i.e., $\mathrm{O} / \mathrm{R}$ ratio at high $\left[\mathrm{Ca}^{2+}\right]$ ), was obtained by clamping the worms at $10 \mathrm{mM}$ of free $\left[\mathrm{Ca}^{2+}\right]$ at different $\mathrm{pH}$ points. In vitro and in vivo $\left[\mathrm{Ca}^{2+}\right]$ calibration curves showed that CalipHluor $_{L y}$ retained its fold-change response of O/R from $1 \mu \mathrm{M}$ to $10 \mathrm{mM}$ at different $\mathrm{pH}$ points. $\mathrm{O} / \mathrm{R}_{\min }$ (i.e., $\mathrm{O} / \mathrm{R}$ ratio at low $\left[\mathrm{Ca}^{2+}\right]$ ) values were calculated from fold change response as function of $\mathrm{pH}$ and normalized to $\mathrm{O} / \mathrm{R}_{\max }$.

$$
\mathrm{O} / \mathrm{R}_{\min }=\frac{1}{4.24+0.12 \times \exp (0.5 \times p H)}
$$

As mentioned above, the $\mathrm{pH}$ in EE, LE and Ly was measured from D/A by using equation (2) at single endosome resolution. $\mathrm{pH}$ and $\mathrm{O} / \mathrm{R}$, were used to calculate $\mathrm{K}_{\mathrm{d}}$ and $\mathrm{O} / \mathrm{R}_{\min }$ from equation (3) and (4). Finally, $\mathrm{K}_{\mathrm{d}}, \mathrm{O} / \mathrm{R}_{\min }, \mathrm{O} / \mathrm{R}$ and $\mathrm{O} / \mathrm{R}_{\max }$ were substituted in the following equation to get $\mathrm{pH}$ corrected free $\left[\mathrm{Ca}^{2+}\right]$ values in endosome by endosome level. 


$$
\text { Free }\left[\mathrm{Ca}^{2+}\right]=K_{d} \times\left[\frac{O / R-O / R_{\min }}{O / R_{\max }-O / R}\right]
$$

Three independent measurements, each with 10 worms, were made for $\mathrm{pH}$ and $\left[\mathrm{Ca}^{2+}\right]$ values in EE, LE and Ly.

\section{Image analysis - $\mathrm{pH}$ corrected $\left[\mathrm{Ca}^{2+}\right]$ images}

High resolution images were acquired using confocal microscopy as mentioned in methods section. Images were acquired in four channels (Alexa 488, FRET, Rhod-5F and Alexa 647 channels) to quantify $\mathrm{pH}$ and $\left[\mathrm{Ca}^{2+}\right]$ at single endosome resolution. To compensate for the pH component in $\mathrm{Ca}^{2+}$ measurements, the $\mathrm{K}_{\mathrm{d}}$ of CalipHluor ${ }_{L y}$ at single endo-lysosomal compartments was calculated based on the $\mathrm{K}_{\mathrm{d}}$ calibration plot discussed above. The $\mathrm{pH}$ of endo-lysosomes was quantified by measuring the donor/acceptor values calibrated across physiological pH (4.0-6.5). Donor (D) and acceptor (A) images were background subtracted by drawing an ROI outside the worms. Donor (D) image was duplicated and a threshold was set to create a binary mask. Background subtracted donor and acceptor images were then multiplied with the binary mask to get processed donor and acceptor images. This processed donor (D) image was divided by the processed acceptor (A) image to get a pseudo color D/A image, using Image calculator module of Image ${ }^{58}$. The $\mathrm{pH}$ value was calculated by using the equation (2) formulated from in vivo and in vitro $\mathrm{pH}$ calibration plot.

The pseudo colored $\mathrm{pH}$ image was processed to get a $\mathrm{K}_{\mathrm{d}}$ image as shown in Fig. 3. $\mathrm{K}_{\mathrm{d}}$ of CalipHluor $_{L y}$ is a function of $\mathrm{pH}$ and this relation is formulated by the $\mathrm{K}_{\mathrm{d}}$ calibration plot in vivo and in vitro using equation (3). For image processing of $\mathrm{pH}$ image to $\mathrm{K}_{\mathrm{d}}$ image, background was set to a non-zero value. The $\mathrm{K}_{\mathrm{d}}$ image represents the affinity of CalipHluor $_{L y}$ for calcium and thus compensating the calcium image $(\mathrm{O} / \mathrm{R})$ with $\mathrm{K}_{\mathrm{d}}$ would precisely represent the calcium levels at single endo-lysosomes. The $\mathrm{pH}$ dependent $\mathrm{K}_{\mathrm{d}}$ compensation is performed according to equation (5), where $O / R_{\max }$ and $O / R_{\min }$ are calculated by incubating CalipHluor coated beads at $10 \mathrm{mM}$ and $1 \mu \mathrm{M}$ respectively. Image calculation were done using image calculator module in ImageJ. This image is multiplied with binary image to bring the background value to zero. The $\mathrm{pH}$ corrected $\mathrm{K}_{\mathrm{d}}$ image were obtained for various mutants for accurate comparison of calcium levels in lysosomes.

\section{Survival assay}

+/mT1 II; cup-5(ok1698)/mT1 [dpy-10(e128)] III nematode strain was used for this assay ${ }^{43}$. Homozygous lethal deletion of cup- 5 gene is balanced by $d p y$-10-marked translocation. Heterozygotes are superficially wildtype [cup5+/-], Dpys (mT1 homozygotes) are sterile, and cup5(ok1698) homozygotes are lethal. cup5+/-L4 worms were placed on plates containing RNAi bacterial strains for L4440 empty vector (positive control), mrp-4, catp-6, catp-5 and clh-6. These worms were allowed to grow for $24 \mathrm{~h}$ and lay eggs after which the adult worms were removed from the plates. The eggs were allowed to hatch and grow to adult for 3 days. The worm plates were then imaged under Olympus SZX-Zb12 Research Stereomicroscope (Olympus Corporation of the Americas, Center Valley, PA, USA) with a Zeiss Axiocam color CCD camera (Carl Zeiss Microscopy, Thornwood, NY, USA). The 
images were analyzed using ImageJ software to count the number of adult worms per plate.

Three independent plates were used for each RNAi background.

\section{Lysosomal size recovery assay}

arIs37 [myo-3p::ssGFP + dpy-20(+)] I. cup-5(ar465) is transgenic nematode strain which secretes GFP from the body muscle cells and this is endocytosed by coelomocytes which show enlarged GFP labelled vesicles as a result of defective degradation caused by cup 5 mutation ${ }^{28}$. Similar to the previous assay, arIs37; cup-5(ar465) L4 worms were placed on plates containing RNAi bacterial strains for empty vector (control), catp-6, catp-5 and mrp-4 (positive control). The worms lay eggs for 24 hours after which they are removed from the plates. The eggs thus hatch and grow to adulthood after which they were imaged to check for lysosomal size differences. Worms were imaged on a Leica TCS SP5 II STED laser scanning confocal microscope (Leica Microsystems, Inc., Buffalo Grove, IL, USA) equipped with $63 \mathrm{X}, 1.4 \mathrm{NA}$, oil immersion objective upon excitation with Argon laser in the Alexa 488 channel. Lysosomal areas were measured using ImageJ. Out 100 lysosomes in arIs37 worms, 7 lysosomes had an area in range of 7.0-9.5 $\mathrm{mm}^{2}$. Enlarged lysosomes are defined as those lysosomes whose diameter is $\geq 33 \%$ of the diameter of the largest lysosome observed in normal N2 worms. We measured the lysosomal area in arIs37; cup-5(ar465) worms in various RNAi bacteria containing plates. Lysosomal size recovery data was plotted as percentage of area occupied by large lysosomes to the total lysosomal area $(n=15$ cells, $>100$ lysosomes).

\section{Bead calibration of CalipHluor ${ }^{m L y}$}

Bead calibration was performed using CalipHluor ${ }^{m L y}$ coated $0.6 \mu \mathrm{m}$ Monodisperse Silica Microspheres (Cospheric, USA). Briefly, silica microspheres were incubated in a solution of $5 \mu \mathrm{M}$ CalipHluor ${ }^{m L y}$ in $20 \mathrm{mM}$ Sodium Acetate buffer $(\mathrm{pH}=5.1)$ and $500 \mathrm{mM} \mathrm{NaCl}$ for 1 $\mathrm{h}^{59,60}$. This binding solution was then spun down and the beads were reconstituted in clamping buffer [HEPES (10 mM), MES (10 mM), sodium acetate (10 mM), EGTA (10 $\mathrm{mM}), \mathrm{KCl}(140 \mathrm{mM}), \mathrm{NaCl}(500 \mathrm{mM})$ and $\left.\mathrm{MgCl}_{2}(1 \mathrm{mM})\right]$. We then varied the amount of $\left[\mathrm{Ca}^{2+}\right]$ from $\sim 0 \mathrm{mM}$ to $10 \mathrm{mM}$ and adjusted the $\mathrm{pH}$ to either $\mathrm{pH} 4.6$ or $\mathrm{pH} 5.1$. The beads were incubated in clamping buffer for 30 mins after which there were imaged on a slide on the IX83 inverted microscope in the $\mathrm{G}, \mathrm{O}$ and $\mathrm{R}$ channels to obtain $\mathrm{G} / \mathrm{R}(\mathrm{pH})$ and $\mathrm{O} / \mathrm{R}$ $\left(\mathrm{Ca}^{2+}\right)$ images.

\section{Cell culture methods and maintenance}

Human dermal fibroblasts (HDF) were a kind gift from Late Professor Janet Rowley's Lab at the University of Chicago and human fibroblast cells harboring mutations in ATP13A2 (L6025) were a kind gift from Krainc Lab, Northwestern University, Chicago. L6025 is homozygous for $1550 \mathrm{C}>\mathrm{T}$. Control and mutant fibroblasts were cultured in Dulbecco's Modified Eagle's Medium (Invitrogen Corporation, USA) containing 10\% heat inactivated Fetal Bovine Serum (FBS) (Invitrogen Corporation, USA), $100 \mathrm{U} / \mathrm{ml}$ penicillin and 100 $\mu \mathrm{g} / \mathrm{mL}$ streptomycin and maintained at $37^{\circ} \mathrm{C}$ under $5 \% \mathrm{CO}_{2}$. 


\section{Competition experiments in cells}

HDF cells were washed with $1 \times$ PBS buffer $\mathrm{pH} 7.4$ prior to labeling. Cells were incubated with $10 \mu \mathrm{M}$ of maleylated BSA (mBSA) or BSA for 15 min and pulsed with media containing $500 \mathrm{nM}$ CalipHluor $^{m L y}$ and $10 \mu \mathrm{M}$ of mBSA or BSA for $1 \mathrm{~h}$ to allow internalization by receptor mediated endocytosis, washed 3 times with $1 \times \mathrm{PBS}$ and then imaged under a wide-field microscope. Whole cell intensities in the Alexa 647 channel was quantified for $>30$ cells per dish. The mean intensity from three different experiments were normalized with respect to the autofluorescence and presented as the fraction internalized.

\section{Colocalization in cells}

We used lysosomes pre-labeled with 10kDa TMR-Dextran (TMR-Dex) to study the trafficking time scales for our probes. TMR Dex was pulsed for $1 \mathrm{~h}$, chased for $16 \mathrm{~h}$ in fibroblast cells followed by imaging. Pre-labeled cells were pulsed with $500 \mathrm{nM}$ of CalipHluor $_{A 647 L y}$ and chased for indicated time and imaged. Cross talk and bleed-through were measured and found to be negligible between the TMR channel and Alexa 647 channel. Pearsons correlation coefficient (PCC) measures the pixel-by-pixel covariance in the signal levels of two images. Tools for quantifying PCC are provided in Fuji software. Pearsons correlation coefficient (PCC) measures the pixel-by-pixel covariance in the signal levels of two images. Tools for quantifying PCC are provided in Fuji software.

\section{In cellulo measurements $\mathrm{pH}$ and calcium measurements}

$\mathrm{pH}$ and calcium clamping were carried out using CalipHluor $^{m L y}$. Fibroblast cells were pulsed for $1 \mathrm{~h}$ and chased for $2 \mathrm{~h}$ with 500nM CalipHluor ${ }^{\mathrm{mL} y}$. Cells are then fixed with 200 $\mathrm{mL} 4 \%$ paraformaldehyde (PFA) for $15 \mathrm{~min}$ at room temperature, washed three times and retained in $1 \times$ PBS. To obtain the intracellular $\mathrm{pH}$ and calcium calibration profile, endosomal calcium concentrations were equalized by incubating the previously fixed cells in the appropriate calcium clamping buffer [HEPES $(10 \mathrm{mM})$, MES $(10 \mathrm{mM})$, sodium acetate $(10 \mathrm{mM})$, EGTA $(10 \mathrm{mM}), \mathrm{KCl}(140 \mathrm{mM}), \mathrm{NaCl}(5 \mathrm{mM})$ and $\left.\mathrm{MgCl}_{2}(1 \mathrm{mM})\right]$ by varying amount of free $\left[\mathrm{Ca}^{2+}\right]$ from $1 \mu \mathrm{M}$ to $10 \mathrm{mM}$ and adjusted to different $\mathrm{pH}$ values. The buffer also contained nigericin $(50 \mu \mathrm{M})$, monensin $(50 \mu \mathrm{M})$ and ionomycin $(20 \mu \mathrm{M})$ and the cells were incubated for $2 \mathrm{~h}$ at room temperature.

For realtime $\mathrm{pH}$ and calcium measurements, fibroblast cells are pulsed with $500 \mathrm{nM}$ of CalipHluor $^{m L y}$ for $1 \mathrm{~h}$, chased for $9 \mathrm{~h}$ ( $8 \mathrm{~h}$ for L0625 cells) and then washed with $1 \times$ PBS and imaged in Hank's Balanced Salt Solution (HBSS). Imaging was carried out on IX83 research inverted microscope (Olympus Corporation of the Americas, Center Valley, PA, USA) using a 100X, 1.42 NA, DIC oil immersion objective (PLAPON, Olympus Corporation of the Americas, Center Valley, PA, USA) and Evolve Delta 512 EMCCD camera (Photometrics, USA).

\section{Data availability}

The data that support the plots within this paper and the findings of this study are available from the corresponding author upon reasonable request. 


\section{Life Sciences Reporting Summary}

Further information on experimental design is available in the Life Sciences Reporting Summary.

\section{Supplementary Material}

Refer to Web version on PubMed Central for supplementary material.

\section{Acknowledgements}

We thank Professor John Kuriyan and Matthew Zajac for valuable comments. We thank the Integrated Light Microscopy facility at the University of Chicago, the Caenorhabditis Genetic Center (CGC) for strains and Ausubel Lab for Arhinger Library RNAi clones. This work was supported by the University of Chicago Women's Board, Pilot and Feasibility award from an NIDDK center grant P30DK42086 to the University of Chicago Digestive Diseases Research Core Center, MRSEC grant no. DMR-1420709, National Center for Advancing Translational Sciences (NCATS) of the National Institutes of Health (NIH) through Grant Number 1UL1TR002389-01 that funds the Institute for Translational Medicine (ITM), Chicago Biomedical Consortium with support from the Searle Funds at The Chicago Community Trust, C-084 and University of Chicago start-up funds to Y.K. Y.K. is a Brain Research Foundation Fellow.

\section{References}

1. Clapham DE Calcium signaling. Cell 131, 1047-1058 (2007). [PubMed: 18083096]

2. Bagur R. \& Hajnóczky G. Intracellular ca2+ sensing: its role in calcium homeostasis and signaling. Mol. Cell 66, 780-788 (2017). [PubMed: 28622523]

3. Yang J, Zhao Z, Gu M, Feng X. \& Xu H. Release and uptake mechanisms of vesicular Ca2+ stores. Protein Cell (2018). doi:10.1007/s13238-018-0523-x

4. Parenti G, Andria G. \& Ballabio A. Lysosomal storage diseases: from pathophysiology to therapy. Annu. Rev. Med 66, 471-486 (2015). [PubMed: 25587658]

5. Plotegher N. \& Duchen MR Crosstalk between Lysosomes and Mitochondria in Parkinson's Disease. Front. Cell Dev. Biol 5, 110 (2017). [PubMed: 29312935]

6. Xu H, Martinoia E. \& Szabo I. Organellar channels and transporters. Cell Calcium 58, 1-10 (2015). [PubMed: 25795199]

7. Calcraft PJ et al. NAADP mobilizes calcium from acidic organelles through two-pore channels. Nature 459, 596-600 (2009). [PubMed: 19387438]

8. Huang P. et al. P2X4 forms functional ATP-activated cation channels on lysosomal membranes regulated by luminal pH. J. Biol. Chem 289, 17658-17667 (2014). [PubMed: 24817123]

9. Kiselyov K. et al. TRPML: transporters of metals in lysosomes essential for cell survival? Cell Calcium 50, 288-294 (2011). [PubMed: 21621258]

10. Lloyd-Evans E. On the move, lysosomal CAX drives Ca2+ transport and motility. J. Cell Biol 212, 755-757 (2016). [PubMed: 27022089]

11. Melchionda M, Pittman JK, Mayor R. \& Patel S. Ca2+/H+ exchange by acidic organelles regulates cell migration in vivo. J. Cell Biol 212, 803-813 (2016). [PubMed: 27002171]

12. Morgan AJ, Davis LC \& Galione A. Imaging approaches to measuring lysosomal calcium. Methods Cell Biol. 126, 159-195 (2015). [PubMed: 25665446]

13. Christensen KA, Myers JT \& Swanson JA pH-dependent regulation of lysosomal calcium in macrophages. J. Cell Sci 115, 599-607 (2002). [PubMed: 11861766]

14. Lloyd-Evans E. et al. Niemann-Pick disease type $\mathrm{C} 1$ is a sphingosine storage disease that causes deregulation of lysosomal calcium. Nat. Med 14, 1247-1255 (2008). [PubMed: 18953351]

15. Garrity AG et al. The endoplasmic reticulum, not the $\mathrm{pH}$ gradient, drives calcium refilling of lysosomes. Elife 5, (2016).

16. Sherwood MW et al. Activation of trypsinogen in large endocytic vacuoles of pancreatic acinar cells. Proc. Natl. Acad. Sci. USA 104, 5674-5679 (2007). [PubMed: 17363470] 
17. Gerasimenko JV, Tepikin AV, Petersen OH \& Gerasimenko OV Calcium uptake via endocytosis with rapid release from acidifying endosomes. Curr. Biol 8, 1335-1338 (1998). [PubMed: 9843688]

18. Johnson DE, Ostrowski P, Jaumouillé V. \& Grinstein S. The position of lysosomes within the cell determines their luminal pH. J. Cell Biol 212, 677-692 (2016). [PubMed: 26975849]

19. Chakraborty K, Veetil AT, Jaffrey SR \& Krishnan Y. Nucleic Acid-Based Nanodevices in Biological Imaging. Annu. Rev. Biochem 85, 349-373 (2016). [PubMed: 27294440]

20. Modi S. et al. A DNA nanomachine that maps spatial and temporal $\mathrm{pH}$ changes inside living cells. Nat. Nanotechnol 4, 325-330 (2009). [PubMed: 19421220]

21. Surana S, Bhat JM, Koushika SP \& Krishnan Y. An autonomous DNA nanomachine maps spatiotemporal pH changes in a multicellular living organism. Nat. Commun 2, 340 (2011). [PubMed: 21654640]

22. Saha S, Prakash V, Halder S, Chakraborty K. \& Krishnan Y. A pH-independent DNA nanodevice for quantifying chloride transport in organelles of living cells. Nat. Nanotechnol 10, 645-651 (2015). [PubMed: 26098226]

23. Modi S, Nizak C, Surana S, Halder S. \& Krishnan Y. Two DNA nanomachines map pH changes along intersecting endocytic pathways inside the same cell. Nat. Nanotechnol 8, 459-467 (2013). [PubMed: 23708428]

24. Chakraborty K, Leung K. \& Krishnan Y. High lumenal chloride in the lysosome is critical for lysosome function. Elife 6, e28862 (2017). [PubMed: 28742019]

25. Toyoshima C. \& Inesi G. Structural basis of ion pumping by Ca2+-ATPase of the sarcoplasmic reticulum. Annu. Rev. Biochem 73, 269-292 (2004). [PubMed: 15189143]

26. Schmidt K, Wolfe DM, Stiller B. \& Pearce DA Cd2+, Mn2+, Ni2+ and Se2+ toxicity to Saccharomyces cerevisiae lacking YPK9p the orthologue of human ATP13A2. Biochem. Biophys. Res. Commun 383, 198-202 (2009). [PubMed: 19345671]

27. Ramonet D. et al. PARK9-associated ATP13A2 localizes to intracellular acidic vesicles and regulates cation homeostasis and neuronal integrity. Hum. Mol. Genet 21, 1725-1743 (2012). [PubMed: 22186024]

28. Fares H. \& Greenwald I. Regulation of endocytosis by CUP-5, the Caenorhabditis elegans mucolipin-1 homolog. Nat. Genet 28, 64-68 (2001). [PubMed: 11326278]

29. Salgado EN, Garcia Rodriguez B, Narayanaswamy N, Krishnan Y. \& Harrison SC Visualization of $\mathrm{Ca} 2+$ loss from rotavirus during cell entry. J. Virol (2018). doi:10.1128/JVI.01327-18

30. Jewett JC, Sletten EM \& Bertozzi CR Rapid Cu-free click chemistry with readily synthesized biarylazacyclooctynones. J. Am. Chem. Soc 132, 3688-3690 (2010). [PubMed: 20187640]

31. Huotari J. \& Helenius A. Endosome maturation. EMBO J. 30, 3481-3500 (2011). [PubMed: 21878991]

32. Hu Y-B, Dammer EB, Ren R-J \& Wang G. The endosomal-lysosomal system: from acidification and cargo sorting to neurodegeneration. Transl Neurodegener 4, 18 (2015). [PubMed: 26448863]

33. Vandecaetsbeek I, Vangheluwe P, Raeymaekers L, Wuytack F. \& Vanoevelen J. The Ca2+ pumps of the endoplasmic reticulum and Golgi apparatus. Cold Spring Harb. Perspect. Biol 3, (2011).

34. Tharkeshwar AK et al. A novel approach to analyze lysosomal dysfunctions through subcellular proteomics and lipidomics: the case of NPC1 deficiency. Sci. Rep 7, 41408 (2017). [PubMed: 28134274]

35. Chapel A. et al. An extended proteome map of the lysosomal membrane reveals novel potential transporters. Mol. Cell Proteomics 12, 1572-1588 (2013). [PubMed: 23436907]

36. Lübke T, Lobel P. \& Sleat DE Proteomics of the lysosome. Biochim. Biophys. Acta 1793, 625-635 (2009). [PubMed: 18977398]

37. Brozzi A, Urbanelli L, Germain PL, Magini A. \& Emiliani C. hLGDB: a database of human lysosomal genes and their regulation. Database (Oxford) 2013, bat024 (2013). [PubMed: 23584836]

38. Schröder BA, Wrocklage C, Hasilik A. \& Saftig P. The proteome of lysosomes. Proteomics 10, 4053-4076 (2010). [PubMed: 20957757] 
39. Cao Q, Yang Y, Zhong XZ \& Dong X-P The lysosomal Ca2+ release channel TRPML1 regulates lysosome size by activating calmodulin. J. Biol. Chem 292, 8424-8435 (2017). [PubMed: 28360104]

40. Sahoo N. et al. Gastric Acid Secretion from Parietal Cells Is Mediated by a Ca2+ Efflux Channel in the Tubulovesicle. Dev. Cell 41, 262-273.e6 (2017). [PubMed: 28486130]

41. Bargal R. et al. Identification of the gene causing mucolipidosis type IV. Nat. Genet 26, 118-123 (2000). [PubMed: 10973263]

42. Schaheen L, Dang H. \& Fares H. Basis of lethality in C. elegans lacking CUP-5, the Mucolipidosis Type IV orthologue. Dev. Biol 293, 382-391 (2006). [PubMed: 16530747]

43. elegans C. Deletion Mutant Consortium. large-scale screening for targeted knockouts in the Caenorhabditis elegans genome. G3 (Bethesda) 2, 1415-1425 (2012). [PubMed: 23173093]

44. Schaheen L, Patton G. \& Fares H. Suppression of the cup-5 mucolipidosis type IV-related lysosomal dysfunction by the inactivation of an $\mathrm{ABC}$ transporter in C. elegans. Development 133, 3939-3948 (2006). [PubMed: 16943270]

45. Fares H. \& Greenwald I. Genetic analysis of endocytosis in Caenorhabditis elegans: coelomocyte uptake defective mutants. Genetics 159, 133-145 (2001). [PubMed: 11560892]

46. van Veen S. et al. Cellular function and pathological role of ATP13A2 and related P-type transport ATPases in Parkinson's disease and other neurological disorders. Front. Mol. Neurosci 7, 48 (2014). [PubMed: 24904274]

47. Schöndorf DC et al. iPSC-derived neurons from GBA1-associated Parkinson's disease patients show autophagic defects and impaired calcium homeostasis. Nat. Commun 5, 4028 (2014). [PubMed: 24905578]

48. Usenovic M, Tresse E, Mazzulli JR, Taylor JP \& Krainc D. Deficiency of ATP13A2 leads to lysosomal dysfunction, a-synuclein accumulation, and neurotoxicity. J. Neurosci 32, 4240-4246 (2012). [PubMed: 22442086]

49. Bras J, Verloes A, Schneider SA, Mole SE \& Guerreiro RJ Mutation of the parkinsonism gene ATP13A2 causes neuronal ceroid-lipofuscinosis. Hum. Mol. Genet 21, 2646-2650 (2012). [PubMed: 22388936]

50. Estrada-Cuzcano A. et al. Loss-of-function mutations in the ATP13A2/PARK9 gene cause complicated hereditary spastic paraplegia (SPG78). Brain 140, 287-305 (2017). [PubMed: 28137957]

\section{References}

51. Grynkiewicz G, Poenie M. \& Tsien RY A new generation of $\mathrm{Ca} 2+$ indicators with greatly improved fluorescence properties. J. Biol. Chem 260, 3440-3450 (1985). [PubMed: 3838314]

52. Collot M. et al. CaRuby-Nano: a novel high affinity calcium probe for dual color imaging. Elife 4, (2015).

53. Moore D. \& Dowhan D. Purification and concentration of DNA from aqueous solutions. Curr. Protoc. Mol. Biol Chapter 2, Unit 2.1A (2002).

54. Brenner S. The genetics of Caenorhabditis elegans. Genetics 77, 71-94 (1974). [PubMed: 4366476]

55. Kamath RS \& Ahringer J. Genome-wide RNAi screening in Caenorhabditis elegans. Methods 30, 313-321 (2003). [PubMed: 12828945]

56. Evangelidis GD \& Psarakis EZ Parametric image alignment using enhanced correlation coefficient maximization. IEEE Trans. Pattern Anal. Mach. Intell 30, 1858-1865 (2008). [PubMed: 18703836]

57. Sauvola J. \& Pietikäinen M. Adaptive document image binarization. Pattern Recognit 33, 225-236 (2000).

58. Schindelin J. et al. Fiji: an open-source platform for biological-image analysis. Nat. Methods 9, 676-682 (2012). [PubMed: 22743772]

59. Engelstein M. et al. An efficient, automatable template preparation for high throughput sequencing. Microb. Comp. Genomics 3, 237-241 (1998). [PubMed: 10027192] 
60. Vandeventer PE et al. Multiphasic DNA adsorption to silica surfaces under varying buffer, $\mathrm{pH}$, and ionic strength conditions. J. Phys. Chem. B 116, 5661-5670 (2012). [PubMed: 22537288] 
(a)

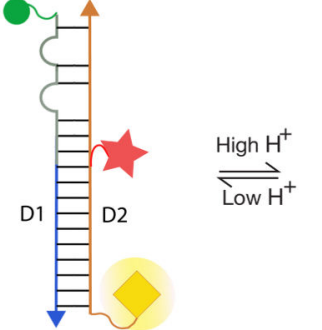

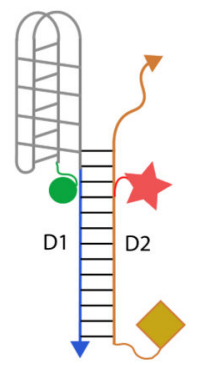

$\vartheta=$

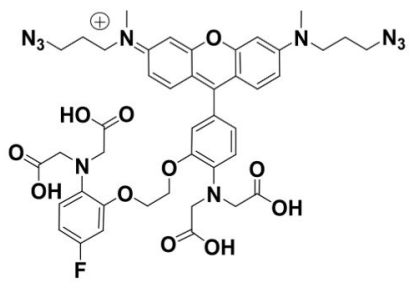

\begin{tabular}{l|l} 
Low \\
$\mathrm{Ca}^{2+}$
\end{tabular}$\| \begin{aligned} & \mathrm{High} \\
& \mathrm{Ca}^{2+}\end{aligned}$

(c)

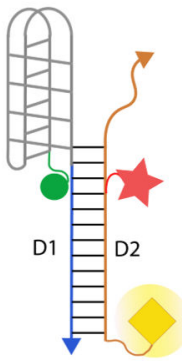

(b)

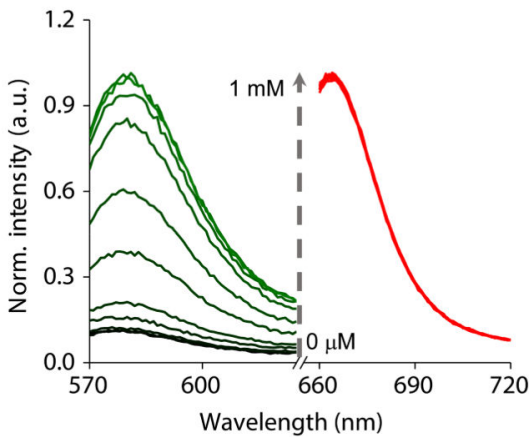

(d)

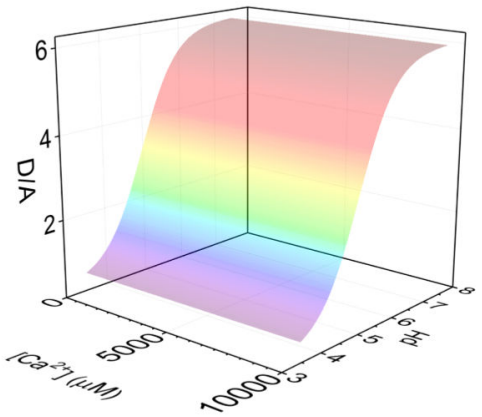

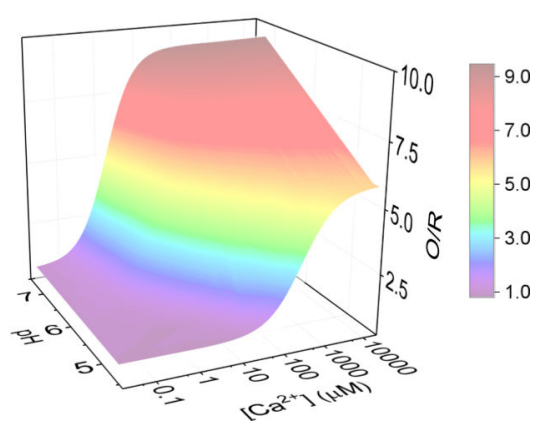

Figure-1: Design and characterization of CalipHluor ${ }_{\mathrm{Ly}}$.

(a) Working principle of CalipHluor Ly $_{\text {. }}$ pH-induced FRET between Alexa488 (donor, D, green sphere) and Alexa647 (acceptor, A, red star) reports on $\mathrm{pH}$ ratiometrically. $\mathrm{A} \mathrm{Ca}{ }^{2+}$ sensitive dye (Rhod-5F, yellow diamond, $\left.\lambda_{\text {ex }}=560 \mathrm{~nm}\right)$ and Alexa647 $\left(\lambda_{\text {ex }}=650 \mathrm{~nm}\right)$ report $\mathrm{Ca}^{2+}$ ratiometrically by direct excitation. (b) Fluorescence emission spectra of CalipHluor $\boldsymbol{L y}_{\boldsymbol{y}}$ corresponding to Rhod-5F (green, O) and Alexa647 (red, R) with increasing $\left[\mathrm{Ca}^{2+}\right]$ at $\mathrm{pH}=$ 7.2. (c) 3D-surface plot of donor to acceptor ratio (D/A) or $\mathrm{pH}$ response of CalipHluor $\boldsymbol{L y}_{\boldsymbol{y}}$ as a function of $\mathrm{pH}$ and $\left[\mathrm{Ca}^{2+}\right]$. (d) 3D-surface plot of the Rhod-5F to Alexa647 ratio (O/R) or $\mathrm{Ca}^{2+}$ response of CalipHluor ${ }_{L y}$ as a function of $\mathrm{pH}$ and $\left[\mathrm{Ca}^{2+}\right]$. 
(a)

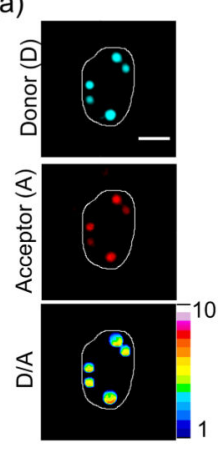

(b)

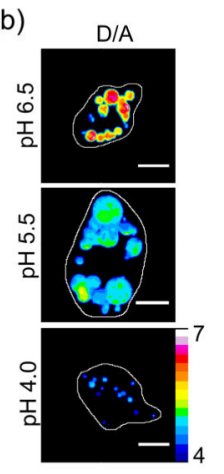

(c)
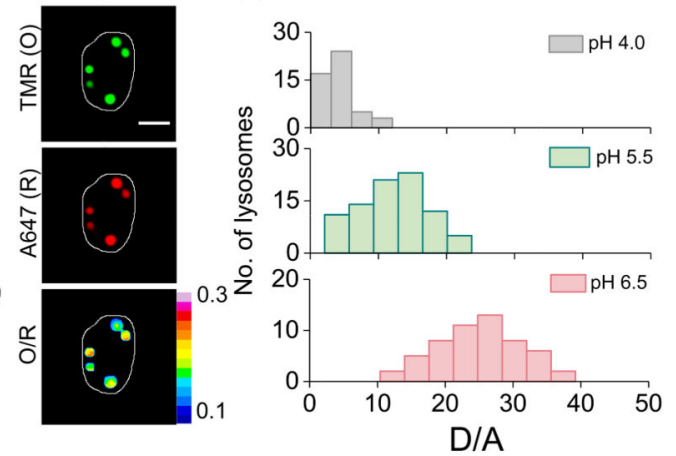

(d)
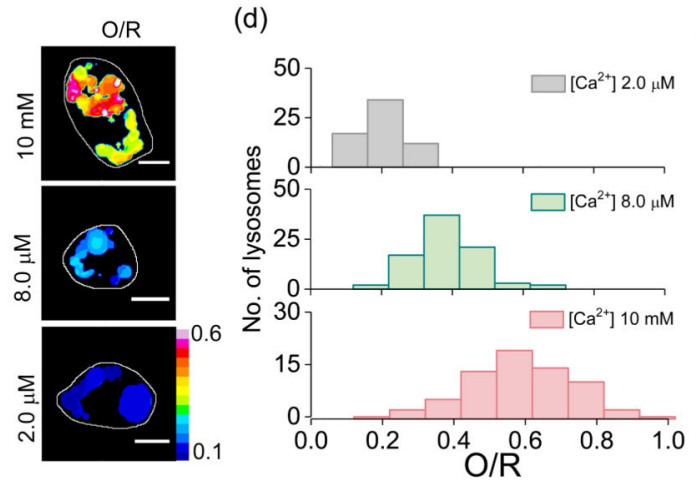

(e)
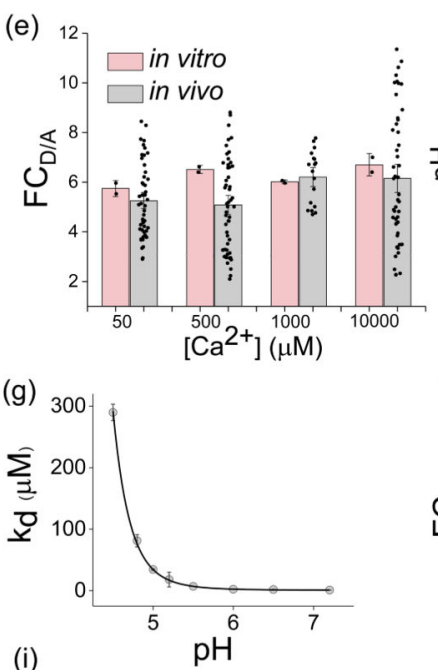

(i)

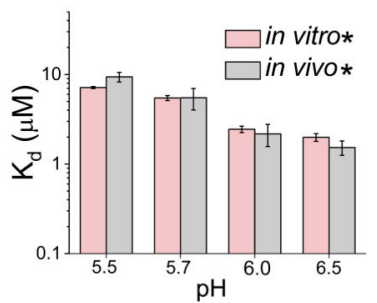

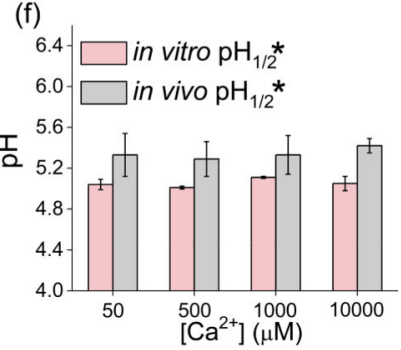

(h)

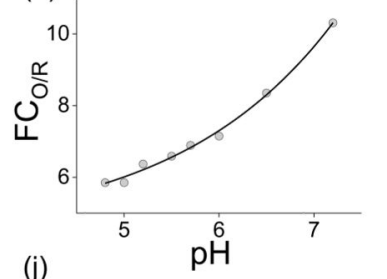

(j)

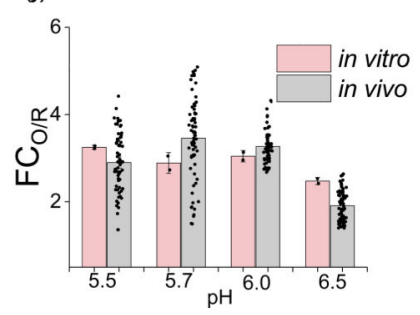

Figure-2: In vivo sensing characteristics of CalipHluor ${ }_{L y}$.

(a) Representative CalipHluor $_{L y}$ labelled coelomocytes imaged in the donor (D,i), acceptor (A,ii), Rhod-5F (O, iii) and Alexa647 (R, iv) channels. D/A (v) and O/R (vi) are the corresponding pixel-wise pseudocolor images. (b) Representative pseudo colored D/A and $\mathrm{O} / \mathrm{R}$ maps of coelomocytes clamped at indicated $\mathrm{pH}$ and free $\left[\mathrm{Ca}^{2+}\right]$ (c) Distribution of D/A ratios of $\geq 50$ endosomes clamped at the indicated $\mathrm{pH}(\mathrm{n}=10$ cells). (d) Distribution of $\mathrm{O} / \mathrm{R}$ ratios of $\geq 50$ endosomes clamped at different indicated free $\left[\mathrm{Ca}^{2+}\right](\mathrm{n}=10$ cells).

Comparison of (e) fold change of D/A ratios from $\mathrm{pH} 4$ to 6.5 and; (f) $\mathrm{pH}_{1 / 2}$ from $\mathrm{pH} 4$ to 6.5 of CalipHluor ${ }_{L y}$ at different $\left[\mathrm{Ca}^{2+}\right]$ obtained in vitro (peach) and in vivo (gray).

CalipHluor $_{L y}(\mathrm{~g})$ Dissociation constant $\mathrm{K}_{\mathrm{d}}(\mu \mathrm{M})$ and (h) fold change of $\mathrm{O} / \mathrm{R}$ as a function of pH. Comparison of (i) fold change in $\mathrm{O} / \mathrm{R}$ ratio from $1 \mu \mathrm{M}$ to $10 \mathrm{mM}\left[\mathrm{Ca}^{2+}\right]$ and (j)

Dissociation constant $\mathrm{K}_{\mathrm{d}}(\mu \mathrm{M})$ of CalipHluor $_{L y}$ at the indicated $\mathrm{pH}$ obtained in vitro (peach) and in vivo (gray). Scale bars, $5 \mu \mathrm{m}$. Data represent mean \pm s.e.m. * Error is obtained from the non-exponential fit. Experiments were repeated thrice independently with similar results. 
a)

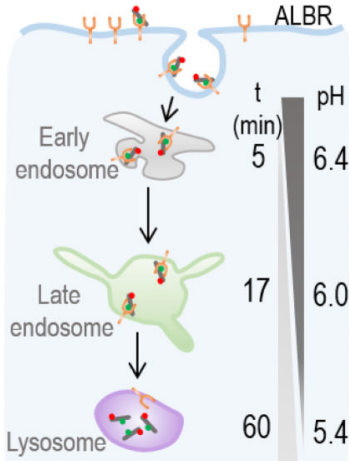

b)

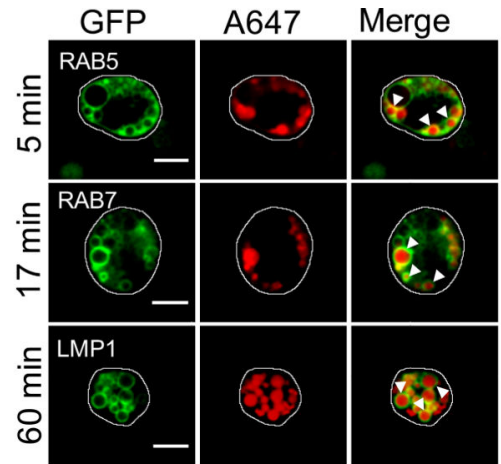

c)

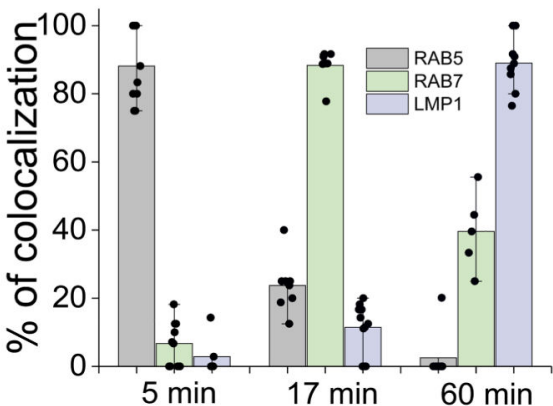

d)
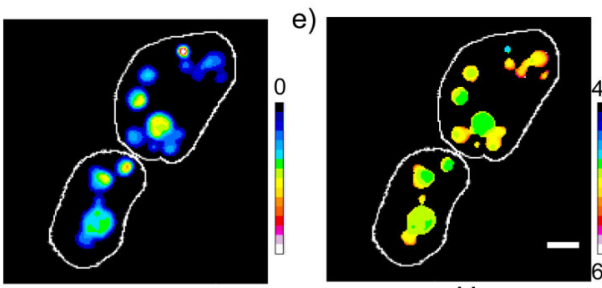

D/A
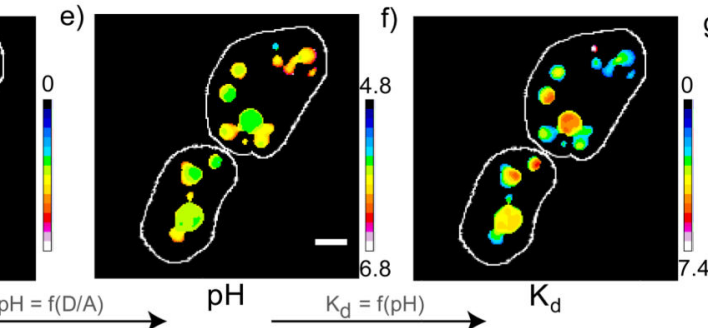

i)

$\mathrm{pH}$
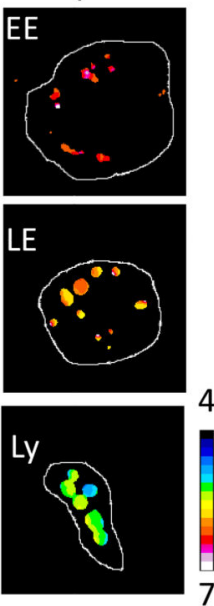

$\mathrm{Ca}^{2+}$
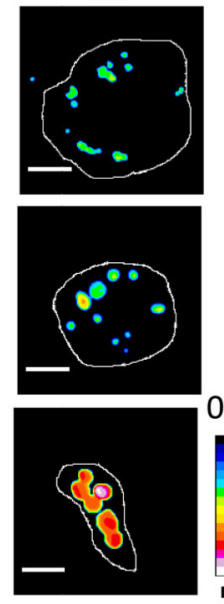

j)

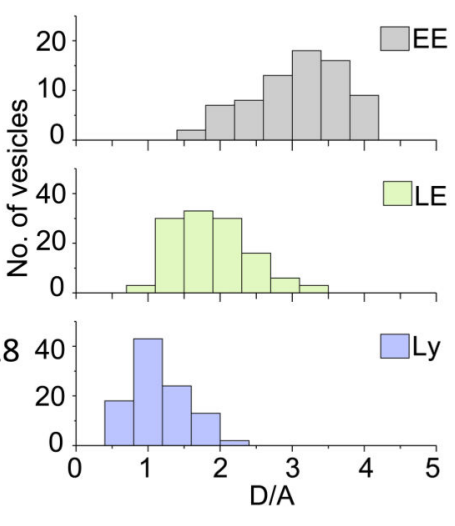

k)

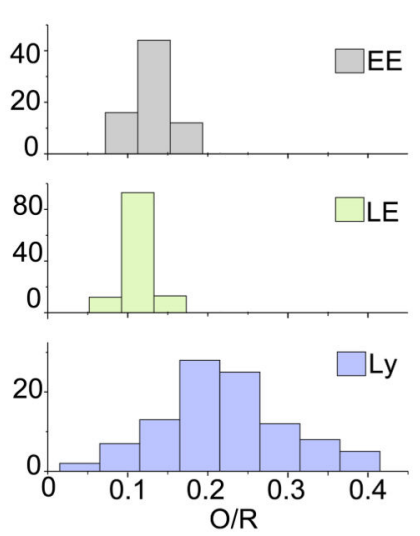

l)

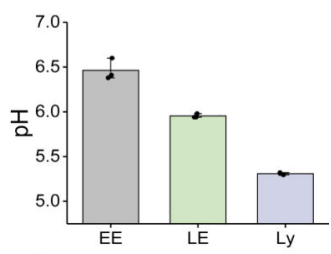

m)

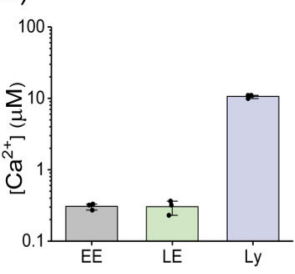

Figure-3: $\mathrm{pH}$ and $\left[\mathrm{Ca}^{2+}\right]$ maps accompanying endosomal maturation.

(a) CalipHluor marks the indicated organelles in coelomocytes time dependently, by scavenger receptor mediated endocytosis. (b) Colocalization of CalipHluor and GFP-tagged markers of endocytic organelles at indicated time points post-injection in nematodes. (c) Quantification of colocalization in (b) ( $\mathrm{n}=10$ cells, $\geq 50$ endosomes) Pseudo color images

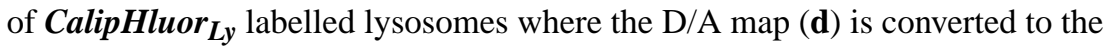
corresponding $\mathrm{pH}$ map (e), the $\mathrm{pH}$ map is converted into a $K_{\mathrm{d}}$ map (f) where the value of $\mathrm{K}_{\mathrm{d}}$ is encoded pixelwise according to the $\mathrm{pH}$ at that pixel; the $K_{\mathrm{d}}$ map (f) is multiplied by the $\mathrm{O} / \mathrm{R}$ map (g) to yield the $\mathrm{Ca}^{2+}$ map (h). (i) Representative pseudocolor $\mathrm{pH}$ and $\mathrm{Ca}^{2+}$ maps of early endosomes (EE), late endosomes (LE) and lysosomes (Ly) labelled with CalipHluor and CalipHluor $_{\text {Ly }}$. (j-l) Distributions of D/A and O/R ratios of EE, LE and Ly from $\mathrm{n}=15$ cells, 50 endosomes. (h) Mean endosomal pH of EE, LE and Ly. (i) Mean endosomal [ $\mathrm{Ca}^{2+}$ ] in EE, LE and Ly data represent the mean \pm s.e.m. Experiments were repeated thrice independently with similar results. 
a)

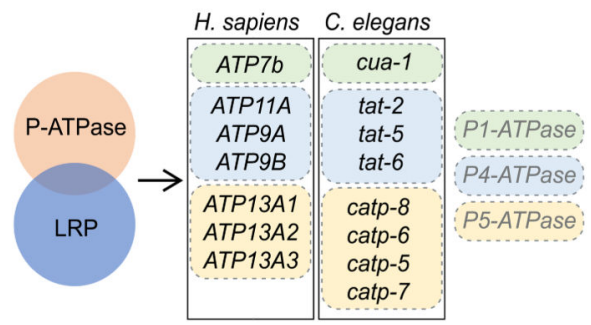

d)

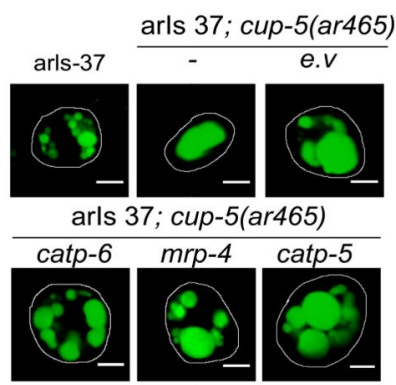

e)

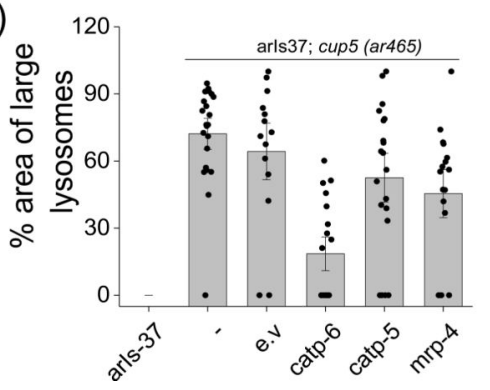

b)

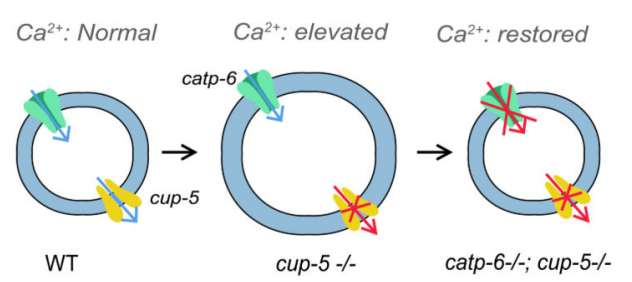

c)

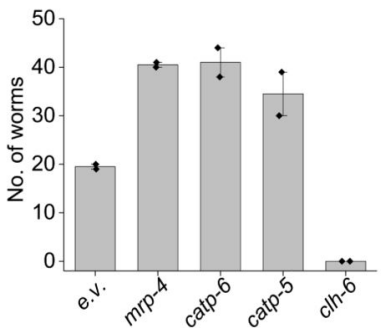

g)

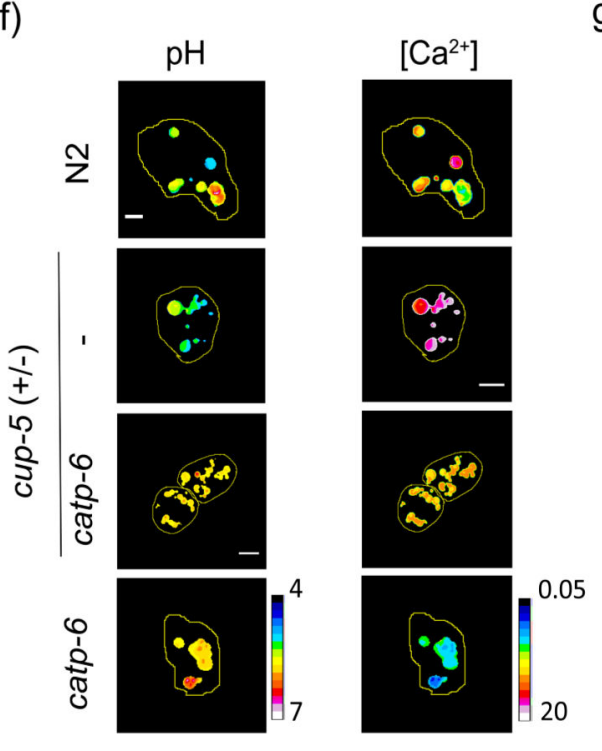

g)

h)

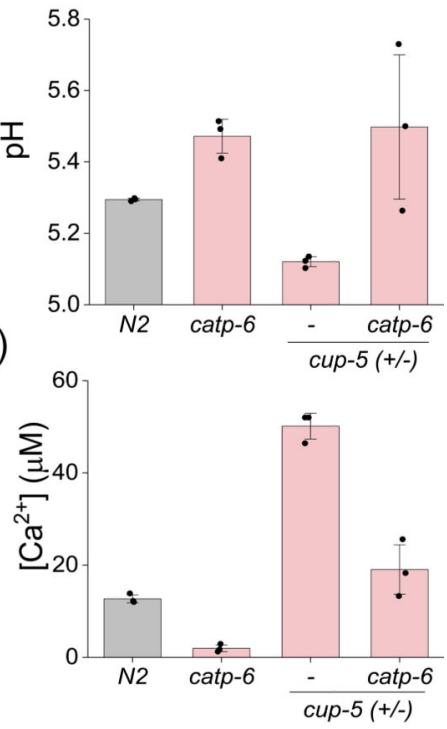

Figure-4: Catp-6 facilitates lysosomal $\mathrm{Ca}^{2+}$ accumulation:

(a) P-type ATPases in human lysosomes obtained from the human Lysosome Gene Database (hLGDB). (b) Functional connectivity between catp-6 and cup-5. (c) Number of adult cup-5 $+/$ progeny where the indicated proteins are knocked down by RNAi. Data represents mean \pm s.e.m. of three independent trials. (d) Representative fluorescence images of arIs37[myo-3p::ssGFP + dpy-20(+)]I and arIs37; cup5(ar465) upon RNAi knockdown of the indicated proteins. (e) Percentage area occupied by enlarged lysosomes in the indicated genetic background. ( $\mathrm{n}=15$ cells, $\geq 100$ lysosomes). (f) $\mathrm{pH}$ and $\mathrm{Ca}^{2+}$ maps in CalipHluor $_{\mathrm{Ly}}$-labeled lysosomes in coelomocytes in indicated genetic backgrounds (g) Mean lysosomal $\mathrm{pH}$ and (h) mean lysosomal $\left[\mathrm{Ca}^{2+}\right]$ in the indicated genetic backgrounds. Data represent the mean \pm s.e.m. Scale bar $5 \mu \mathrm{m}$. Data represent mean \pm s.e.m. Experiments were repeated thrice independently with similar results. 
a)

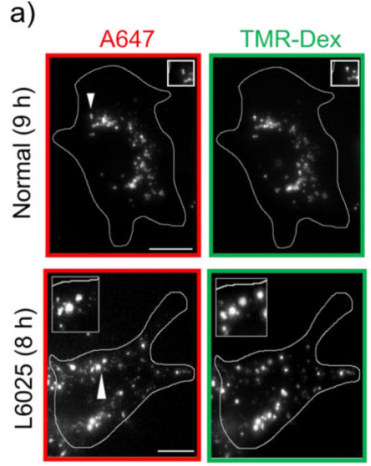

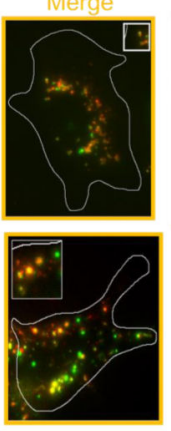

b)
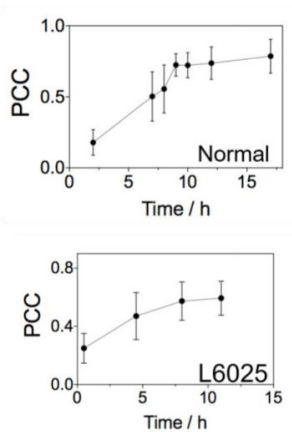

c)

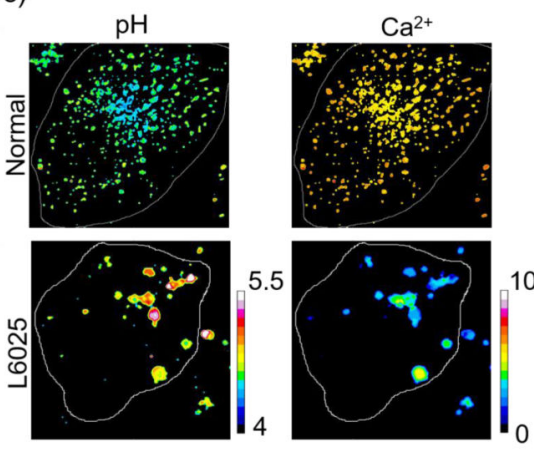

d)
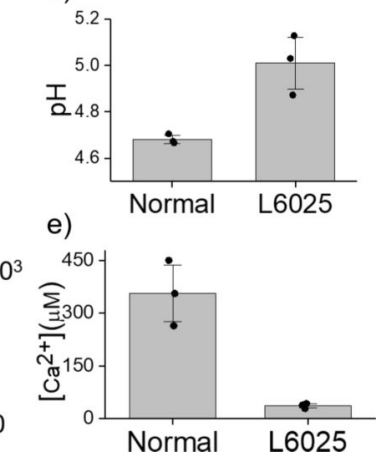

Figure-5: CalipHuor ${ }^{m L y}$ maps lysosomal $\mathrm{Ca}^{2+}$ in human cells:

a) Representative images of lysosomes in fibroblast cells from normal individuals and Kufor Rakeb syndrome patients (L6025S) labelled with TMR dextran (TMR; green) and CalipHluor $^{\text {mLy }}$ (Alexa647, red). b) Pearson's correlation coefficient (PCC) of colocalization

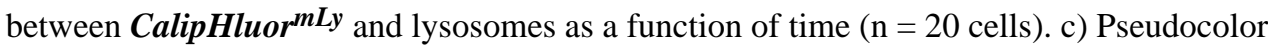
$\mathrm{pH}$ and $\mathrm{Ca}^{2+}$ maps of lysosomes in normal and L6025 fibroblasts (d) Mean lysosomal pH and (e) mean lysosomal $\left[\mathrm{Ca}^{2+}\right]$ in normal and L6025 fibroblasts. ( $\mathrm{n}=5$ cells; 50 endosomes) Scale bar: $10 \mu \mathrm{m}$. Data represent mean \pm s.e.m. Experiments were repeated thrice independently with similar results. 